\title{
Bimetallic Salen-Based Compounds and Their Potential Applications
}

\author{
Alba Finelli, Sarah-Luise Abram, Nelly Hérault, Aurélien Crochet, and Katharina M. Fromm*
}

\begin{abstract}
The new bimetallic coordination compounds $\left[\mathrm{LNiAg}\left(\mathrm{NO}_{3}\right)\right], \quad\left[\mathrm{LCuMn}\left(\mathrm{NO}_{3}\right)_{2}\right], \quad\left[\mathrm{LCuCu}\left(\mathrm{NO}_{3}\right)_{2}\right], \quad[\mathrm{LCuZn}-$ $\left.\left(\mathrm{NO}_{3}\right)_{2}\right]$, and $\left[\left\{\mathrm{LCuBi}\left(\mathrm{NO}_{3}\right)_{3}\right\}(\mathrm{ACN})\right]$ have been synthesized from a salen-type ligand $\mathrm{L}$ containing two distinct coordination sites to accommodate (different) metal ions M1 and M2. In the solid state, the formation of $1: 1$ compounds (LCu:M2) is always observed, but interactions between the compounds lead to differences in packing. For example, a head-to-tail arrangement along the crystallographic $b$-axis is observed in the case of the $\mathrm{LCuBi}$ compound, and the $\mathrm{LNiAg}$ compound is polymeric, while its $\mathrm{Cu}$ homologue $\mathrm{LCuAg}$ forms a discrete dimer. Given the inherent potential of the preorganizing, two metal ions using $\mathrm{L}$ could be used to synthesize nanoscale copper-bismuth and -manganese mixed metal oxides as a function of the temperature. The combination of different bioactive metal ions within one ligand system was furthermore explored for antimicrobial efficiency.
\end{abstract}

\section{INTRODUCTION}

Arranging different metal ions in space and number through compartmentalization in a ligand is essential in materials science and in biology. ${ }^{1-3}$ The close association of at least two metal ions can enhance existing properties or even lead to new features $^{4}$ in compounds such as coordination polymers, ${ }^{5}$ multimetallic complexes, ${ }^{6,7}$ or mixed metal oxide materials, ${ }^{8}$ thus opening new routes to multifunctional materials. ${ }^{9}$ Among these, mixed metal oxides are nowadays especially sought for their magnetic, ${ }^{10}$ superconducting, ${ }^{11}$ catalytic, ${ }^{12}$ and optical ${ }^{13}$ properties. They are typically synthesized through solid-state reactions requiring high temperatures, or by milder methods such as sol-gel techniques ${ }^{14}$ or metal organic chemical vapor deposition $((\mathrm{MO}-) \mathrm{CVD}),{ }^{15}$ for which volatile metal compounds such as alkoxides or diketones are needed. ${ }^{16}$ However, oligomerization and the lack of metal ion control, together with insufficient volatilities and stabilities, can be major limitations of these procedures. ${ }^{17}$ Therefore, the idea to compartmentalize the metal ions within a single-source precursor (SSP), ${ }^{18}$ such as salen-derivatives, is an attractive alternative. ${ }^{19}$ The use of such multitopic precursors allows an intimate and organized mixing of the metal ions at the molecular level, facilitating the crystallization process of the mixed metal oxides under mild conditions and decreasing the formation of side products. ${ }^{20}$ This synthetic strategy often leads to monodisperse and phase-pure nanocrystals with particular morphologies. $^{21}$

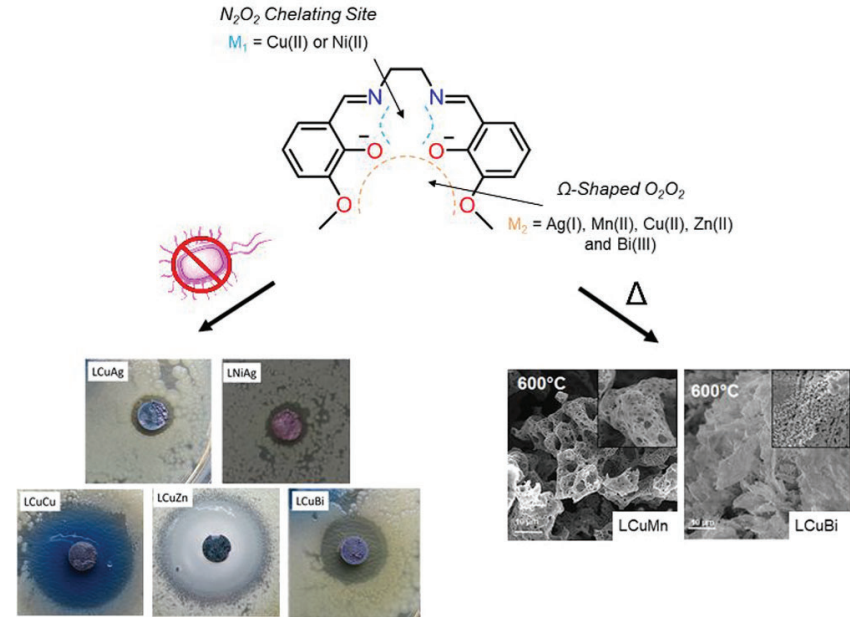

Another application that we are interested in in the context of multimetallic compounds is the combat against bacterial infections. ${ }^{22}$ Recently, considerable efforts have been undertaken to develop metal-based antimicrobially active compounds that could serve as alternatives to traditional antibiotics regarding the rise in infections caused by multidrug-resistant bacteria. $^{23}$ It has, for example, been shown that the combination of different metal ions lowered the bactericidal concentrations, thus overcoming toxicity limitations known for metal based drugs. ${ }^{24}$ Such synergistic effects have also been reported for associations of metal ions with classical antibiotics $^{25}$ or organic acids. ${ }^{26}$ As a result, the combination of different drugs has turned out to be an efficient tool to broaden the therapeutic window of a given antibiotic compound. ${ }^{27}$

For such biological applications, but also to obtain mixed metal oxide materials, the design and development of specific ligand systems are thus crucial for the formation of precise and clean multimetallic compounds. ${ }^{28}$ Salen-type ligands can efficiently bind to transition-metal ions in a tetradentate mode through their $\mathrm{N}_{2} \mathrm{O}_{2}$ site to form very stable complexes. They are versatile chelating ligands in coordination chemistry 
thanks to their tunable design, ${ }^{29,30}$ and multiple functional compartments can be created by simple substitution of the ligand, generating macrocycle-type compounds for the coordination of different metal ions. ${ }^{31,32}$

Here, we report the study of bimetallic compounds based on a salen-derivative, $\mathrm{H}_{2} \mathrm{~L}$, possessing two distinct coordination sites. We have previously studied the structural trends of $\mathrm{LCu}$ and $\mathrm{LNi}$ compounds in combination with alkali and alkaline earth metal ions, and found that the $\mathrm{Cu}$-compounds formed mostly chains with alternatingly arranged $\mathrm{LCu}$-moieties, while the $\mathrm{Ni}$-analogues had the $\mathrm{LNi}$ entities arranged on the same side of the polymeric chain. ${ }^{33}$ Now, the greater interest in the optical, conductive, and catalytic properties of coppermanganese and copper-bismuth oxides, ${ }^{34,35}$ as well as the efficient antimicrobial properties of silver, copper, zinc, and bismuth ions, encouraged us to combine $\mathrm{LCu}(\mathrm{II})$ with $\mathrm{Ag}(\mathrm{I})$, $\mathrm{Mn}(\mathrm{II}), \mathrm{Cu}(\mathrm{II}), \mathrm{Zn}(\mathrm{II}), \mathrm{Bi}(\mathrm{III})$, and, for comparison, LNi(II) with $\mathrm{Ag}(\mathrm{I})$ as bimetallic compounds. A structural study of the different compounds was carried out by single crystal X-ray diffraction, and their potential as single-source precursors for the generation of nanoscale, mixed-metal oxides has been investigated together with their potential antimicrobial properties.

\section{EXPERIMENTAL SECTION}

Material and Methods. All experiments were performed in air and at RT. Ligand $\mathrm{H}_{2} \mathrm{~L}$ was prepared according to the procedure reported by Avecilla et al. previously. ${ }^{36}$ Monometallic complex ligands $\mathbf{L C u}, \mathbf{L N i}$, and $\mathbf{L Z n}$ were prepared as described in the literature. ${ }^{37,38}$ All chemicals were commercial products of reagent grade and were used without further purification. For the numbering of the obtained compounds, we chose to start with the lowest charged M2, hence $\mathrm{Ag}$ (I) compounds, then the $\mathrm{M}$ (II) ions as they come in the periodic table, and finally the example with a $\mathrm{M}$ (III) ion as M2. Elemental analyses for $\mathrm{C}, \mathrm{H}$, and $\mathrm{N}$ were carried out using a FLASH 2000 Organic Elemental Analyzer. Some of the results indicate residual solvent, e.g., water, after drying. In most cases, the values found for hydrogen content are lower than expected despite trying many times, and this phenomenon may be due to the possible interferences with the diverse metal ions during the mineralization. Indeed, the elemental analysis can be affected by the incomplete conversion of the compounds or by the formation of compounds leading to the corrosion of analytical instruments, both possibly leading to underestimated results. However, mass spectra (ESI-TOF, positive mode) for all compounds could be recorded with a Bruker esquire HCT spectrometer with a DMF/ACN mixture as solvent. The crystallographic data of single crystals were collected with Mo K $\alpha$ radiation $(\lambda=0.71073 \AA)$. All measurements were performed at 250 or $200 \mathrm{~K}$, with Stoe IPDS-II or IPDS-II T diffractometers equipped with Oxford Cryosystem open-flow cryostats. ${ }^{39}$ Single crystals were picked under the microscope, and placed in inert oil. All crystals were mounted on loops, and all geometric and intensity data were taken from one single crystal. The absorption corrections were partially integrated in the data reduction procedure. ${ }^{40}$ The structures were solved and refined using full-matrix least-squares on $F^{2}$ with the SHELX-2014 package. ${ }^{41}$ All atoms (except hydrogen atoms) were refined anisotropically. Hydrogen atoms were refined when possible, and otherwise added using the riding model position parameters. Crystallographic data can be found in the Supporting Information (see Table S1). CIF files can be obtained from the Cambridge Crystallographic Data Centre, CCDC-1860979 (1), CCDC-1861009 (2), CCDC-1860982 (3), CCDC-1860981 (4), CCDC-1860983 (5), and CCDC-1860980 (6). Additional crystal structures with similar metal ion combinations but different counterions or solvent (CCDC1861005 ( LCuMn $\mathbf{C l}_{2}$ ), CCDC-1861004 (LCuMn $\mathbf{C l O}_{4}$ ), and CCDC-1861006 (LCuMn OAc) can be found in the Supporting Information (Figures S3-S5, Table S4). Copies of these data can be obtained free of charge from the Cambridge Crystallographic Data Centre through www.ccdc.cam.ac.uk or e-mail, deposit@ccdc.cam.ac. uk. Powder X-ray diffractograms were collected on a Stoe STADIP using $\mathrm{Cu} \mathrm{K} \alpha 1$ radiation (1.5406 $\AA$ ) using a Mythen detector (Figures S6-S10). TGA were recorded on a Mettler Toledo TGA/SDTA851. Being paramagnetic, ${ }^{1} \mathrm{H}$ NMR measurements could not be performed on compounds $1-6$. The ligand $\mathrm{H}_{2} \mathrm{~L}$ and the complex $\mathrm{LCu}$ obtained by chelating the ligand to the copper ion were synthesized as described in the literature. $^{36,37}$ Specific surface areas of the samples were determined using the Brunauer-Emmett-Teller (BET) method by performing nitrogen sorption measurements using a Micromeritics ASAP 2010 instrument. The adsorption and desorption experiments were carried out at $77 \mathrm{~K}$ after initial pretreatment of the samples by degassing at $250{ }^{\circ} \mathrm{C}$ for $3 \mathrm{~h}$.

Synthesis of LCuAg (1). A solution of $\mathrm{AgNO}_{3}$ (41.61 mg, 0.245 $\mathrm{mmol})$ in acetonitrile/ethanol $(7: 3,30 \mathrm{~mL})$ was added to a solution of $\mathrm{LCu}$ (100 mg, $0.245 \mathrm{mmol}$ ), previously dissolved in a mixture of acetonitrile/ethanol $(7: 3,30 \mathrm{~mL})$. After stirring overnight at room temperature, the precipitate was collected and dried under vacuum to afford compound 1 (119.32 mg, $0.212 \mathrm{mmol}, 87 \%)$. After few days, red, block-like single crystals suitable for X-ray crystallographic analysis were obtained by slow evaporation of the mother liquor. ESIMS $(m / z): 558.95[\mathrm{M}+\mathrm{H}]^{+}$, where $\mathrm{M}$ corresponds to "LCuAg". Anal. Calcd for $\mathrm{C}_{18} \mathrm{H}_{18} \mathrm{AgCuN}_{3} \mathrm{O}_{7}$, corresponding to "LCuAg" (5): C, 38.62; H, 3.24; N, 7.51\%. Found: C, 38.65; H, 1.80; N, 7.42\%.

Synthesis of $\left[\mathrm{LNiAg}\left(\mathrm{NO}_{3}\right)\right]$ as "LNiAg" (2), [LCUMn $\left.\left(\mathrm{NO}_{3}\right)_{2}\right]$ as "LCuMn" (3), [LCuCu(NO $\left.)_{2}\right)_{2}$ "LCuCu" (4), [LCuZn $\left.\left(\mathrm{NO}_{3}\right)_{2}\right]$ as "LCUZn" (5), or $\left[\left\{L C U B i\left(N_{3}\right)_{3}\right\}(A C N)\right]$ "LCUBi" (6). These compounds were prepared by the same method as described above, by reacting $\mathrm{LCu}$ in an acetonitrile/ethanol (7:3) solution with 1 equiv of the appropriate metal salt. The metal salts used were as follows: $\mathrm{AgNO}_{3}(41.61 \mathrm{mg}$, $0.245 \mathrm{mmol})$ for 1 and $2, \mathrm{Mn}\left(\mathrm{NO}_{3}\right)_{2} \cdot 4 \mathrm{H}_{2} \mathrm{O}(61.49 \mathrm{mg}, 0.245 \mathrm{mmol})$ for $3, \mathrm{Cu}\left(\mathrm{NO}_{3}\right)_{2}(45.95 \mathrm{mg}, 0.245 \mathrm{mmol})$ for $4, \mathrm{Zn}\left(\mathrm{NO}_{3}\right)_{2}(46.40$ $\mathrm{mg}, 0.245 \mathrm{mmol})$ for 5 , and $\mathrm{Bi}\left(\mathrm{NO}_{3}\right)_{3} \cdot 5 \mathrm{H}_{2} \mathrm{O}(118.84 \mathrm{mg}, 0.245$ $\mathrm{mmol}$ ) for 6.

Data for LNiAg (2). Orange needle-like single crystals suitable for $\mathrm{X}$-ray crystallographic analysis were obtained by slow evaporation of the mother liquor. Yield: $82 \%$ (0.201 mmol, $111.48 \mathrm{mg})$. ESI-MS ( $\mathrm{m} /$ $z): 553.95[\mathrm{M}+\mathrm{H}]^{+}$, where $\mathrm{M}$ corresponds to "LNiAg". Anal. Calcd for $\mathrm{C}_{18} \mathrm{H}_{18} \mathrm{AgCuN}_{3} \mathrm{O}_{7}$ (5): C, 38.62; H, 3.24; N, 7.51\%. Found: C, $38.65 ; \mathrm{H}, 1.80 ; \mathrm{N}, 7.42 \%$.

Data for LCUMn (3). Red plate-like single crystals suitable for X-ray crystallographic analysis were obtained by vapor-phase diffusion of diethyl ether into the mother liquor of the reaction in a long tube. Yield: $90 \%$ (0.225 mmol, $125.43 \mathrm{mg})$. ESI-MS $(\mathrm{m} / z)$ : 506.95 [M$\left.\mathrm{NO}_{3}\right]^{+}$, where $\mathrm{M}$ corresponds to "LCuMn". Anal. Calcd for $\mathrm{C}_{18} \mathrm{H}_{20} \mathrm{CuMnN}_{4} \mathrm{O}_{11}$, corresponding to "LCuMn" (3) with one molecule of water: C, 36.8; H, 3.44; N, 9.36\%. Found: C, 36.8; H, 1.7; N, 9.49\%.

Data for LCUCu (4). Purple plate-like single crystals suitable for Xray crystallographic analysis were obtained by vapor phase diffusion of diethyl ether into the mother liquor of the reaction. Yield: $82 \%$ (0.201 mmol, $116 \mathrm{mg})$. ESI-MS $(\mathrm{m} / z): 513.95\left[\mathrm{M}-\mathrm{NO}_{3}\right]^{+}$, where $\mathrm{M}$ corresponds to " $\mathrm{LCuCu}$ ". Anal. Calcd for $\mathrm{C}_{18} \mathrm{H}_{18} \mathrm{Cu}_{2} \mathrm{~N}_{4} \mathrm{O}_{10}$, corresponding to "LCuCu" (3): C, 37.44; H, 3.14; N, 9.70\%. Found: C, 37.09; H, 2.48; N, 9.45\%.

Data for LCUZn (5). Purple plate-like single crystals suitable for Xray crystallographic analysis were obtained by slow evaporation of the mother liquor reaction. Yield: $91 \%(0.223 \mathrm{mmol}, 129.15 \mathrm{mg})$. ESI-MS $(m / z): 577.96[\mathbf{M}+\mathbf{H}]^{+}$, where $\mathbf{M}$ corresponds to the asymmetric unit of "LCuZn". Anal. Calcd for $\mathrm{C}_{18} \mathrm{H}_{18} \mathrm{CuN}_{4} \mathrm{O}_{10} \mathrm{Zn}$, corresponding to the asymmetric unit of "LCuZn" (4): C, 37.32; H, 3.13; N, 9.67\%. Found: C, 37.44; H, 2.27; N, 9.25\%.

Data for LCUBi (6). Green needle-like single crystals suitable for Xray crystallographic analysis were obtained by vapor phase diffusion of diethyl ether into the mother liquor of the reaction. Yield: $88 \%(0.215$ mmol, $169.22 \mathrm{mg})$. ESI-MS $(\mathrm{m} / z)$ : $722.00\left[\mathrm{M}-\mathrm{NO}_{3}\right]^{+}$, where $\mathrm{M}$ corresponds to "LCuBi" without ACN molecule. Anal. Calcd for $\mathrm{C}_{18} \mathrm{H}_{20} \mathrm{BiCuN}_{5} \mathrm{O}_{14}$, corresponding to "LCuBi" with one molecule of 
Scheme 1. (a) Synthetic Route of $\mathrm{H}_{2} \mathrm{~L}$ and (b) Its Two Potential Coordination Sites

a)

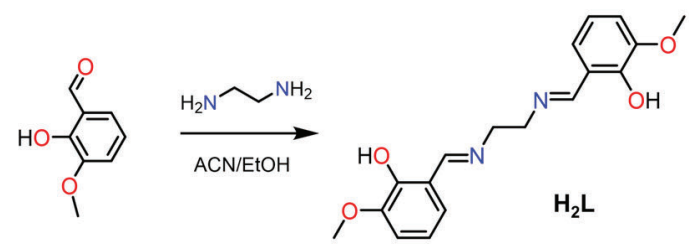

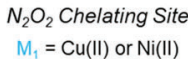

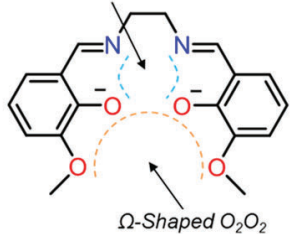

$M_{2}=A g(I), M n(I I), C u(I I), Z n(I I)$ and $\mathrm{Bi}(\mathrm{III})$

Table 1. Crystallographic Data of 1-6

\begin{tabular}{|c|c|c|c|c|c|c|}
\hline & “LCuAg” (1) & “LNiAg” (2) & “LCuMn” (3) & "LCuCu” (4) & "LCuZn" (5) & “LCuBi” (6) \\
\hline Formula & $\mathrm{C}_{18} \mathrm{H}_{18} \mathrm{AgCuN}_{3} \mathrm{O}_{7}$ & $\mathrm{C}_{18} \mathrm{H}_{18} \mathrm{AgN}_{3} \mathrm{NiO}_{7}$ & $\mathrm{C}_{18} \mathrm{H}_{18} \mathrm{CuMnN}_{4} \mathrm{O}_{10}$ & $\mathrm{C}_{18} \mathrm{H}_{18} \mathrm{Cu}_{2} \mathrm{~N}_{4} \mathrm{O}_{10}$ & $\mathrm{C}_{36} \mathrm{H}_{36} \mathrm{Cu}_{2} \mathrm{~N}_{8} \mathrm{O}_{20} \mathrm{Zn}_{2}$ & $\mathrm{C}_{20} \mathrm{H}_{21} \mathrm{BiCuN}_{6} \mathrm{O}_{13}$ \\
\hline$M_{\mathrm{w}}$ & 559.76 & 536.79 & 568.84 & 577.44 & 1158.55 & 825.95 \\
\hline$T[\mathrm{~K}]$ & 250 & 200 & 200 & 250 & 250 & 200 \\
\hline Lattice & monoclinic & orthorhombic & monoclinic & monoclinic & triclinic & orthorhombic \\
\hline Space group & $\mathrm{C} 2 / \mathrm{c}$ & $P 2_{1} 2_{1} 2_{1}$ & $P 2 / \mathrm{n}$ & $P 2_{1} / \mathrm{n}$ & $P \overline{1}$ & $P 2_{1} 2_{1} 2_{1}$ \\
\hline$a[\AA]$ & $23.049(4)$ & $6.7481(2)$ & $13.1448(6)$ & $8.8762(6)$ & $7.7915(8)$ & $8.6303(9)$ \\
\hline$b[\AA]$ & $14.9081(16)$ & $16.3551(5)$ & $10.9131(4)$ & $22.1395(16)$ & $10.5248(10)$ & $15.3489(16)$ \\
\hline$c[\AA]$ & $11.611(2)$ & $17.5677(5)$ & $14.2298(9)$ & $10.5889(7)$ & $13.3319(13)$ & $19.784(2)$ \\
\hline$\alpha\left[^{\circ}\right]$ & 90 & 90 & 90 & 90 & $83.988(8)$ & 90 \\
\hline$\beta\left[^{\circ}\right]$ & $104.674(13)$ & 90 & $99.361(4)$ & $95.903(6)$ & $78.881(8)$ & 90 \\
\hline$\gamma\left[^{\circ}\right]$ & 90 & 90 & 90 & 90 & $72.117(7)$ & 90 \\
\hline$V\left[\AA^{3}\right]$ & $3859.6(10)$ & $1928.87(10)$ & $2014.09(18)$ & $2069.8(2)$ & $1019.70(18)$ & $2620.7(5)$ \\
\hline $\mathrm{Z}$ & 8 & 4 & 4 & 4 & 2 & 4 \\
\hline$d_{\text {calc }}\left[\mathrm{g} \mathrm{cm}^{-3}\right]$ & 1.927 & 1.839 & 1.876 & 1.853 & 1.887 & 2.093 \\
\hline$R_{1} / \mathrm{w} R_{2}[\mathrm{I}>2 \sigma(\mathrm{I})]$ & $0.0354 / 0.0782$ & $0.0440 / 0.0938$ & $0.1053 / 0.2530$ & $0.0419 / 0.1019$ & $0.0228 / 0.0521$ & $0.0498 / 0.1169$ \\
\hline
\end{tabular}

water (2): C, 26.93; H, 2.51; N, 8.72\%. Found: C, 26.33; H, 1.24; N, $8.37 \%$.

Thermal Processes. Samples of the two compounds $\mathbf{3}$ and $\mathbf{6}$ were heated under air to four different temperatures: 300, 400, 500, and $600{ }^{\circ} \mathrm{C}$ during $4 \mathrm{~h}$. The morphology and the composition of the obtained materials were explored by scanning electron microscopy (SEM) and powder X-ray diffraction (PXRD). Average crystallite sizes were estimated using the Scherrer method. Using BET, the surface area $\left(S_{\mathrm{BET}}\right)$ and pore size distribution $\left(V_{\mathrm{BJH}}\right)$ were calculated. In order to follow the decomposition of $\mathbf{3}$ and $\mathbf{6}$ upon heating, the thermal behavior of the mixed metal compounds 3 and 6 was studied by TGA over a range of $30-600{ }^{\circ} \mathrm{C}$ in air.

As both compounds 3 and 6 were prepared from nitrate salts, for comparison, a mixture of stoichiometric amounts $(1: 1)$ of $\mathrm{Cu}\left(\mathrm{NO}_{3}\right)_{2}$ and $\mathrm{Mn}\left(\mathrm{NO}_{3}\right)_{2}$ or $\mathrm{Bi}\left(\mathrm{NO}_{3}\right)_{3}$ was ball-milled and heated at $600{ }^{\circ} \mathrm{C}$ in order to compare the results with the mixed metal oxides resulting from the combustion of our single-source precursors.

Agar Diffusion Test. An overnight culture of Escherichia coli 25922 (E. coli) in Müller-Hinton (MH) broth was diluted to the concentration of $1 \times 10^{6} \mathrm{cfu} / \mathrm{mL}$ using the McFarland standard. 100 $\mu \mathrm{L}$ were spread on $8.5-\mathrm{cm}$-diameter $\mathrm{MH}$ agar dishes. After $5 \mathrm{~min}$ drying, pellets of the compounds were placed on the agar and gently pressed with sterile tweezers. The agar plates were incubated upside down at $37^{\circ} \mathrm{C}$ overnight. The diameter of the inhibition zone (ZOI) was measured using ImageJ on photographs of the agar plates with the diameter of the plates as the reference scale. The initial diameter of the pressed pellets is subtracted before dividing by two for the ZOI radius.

Broth Microdilution Test. An overnight culture of E. coli in Müller Hinton $(\mathrm{MH})$ broth was diluted to $1 \times 10^{7} \mathrm{cfu} / \mathrm{mL}$ using the McFarland standard. The powders of the compounds or the respective nitrate salts were suspended by sonication in $\mathrm{MH}$ broth and diluted to create a concentration series that was then inoculated with the overnight $E$. coli culture to reach a final inoculum of $1 \times 10^{6}$ $\mathrm{cfu} / \mathrm{mL}$. Duplicates of $0.5 \mathrm{~mL}$ for each concentration were incubated in suitable well plates for $24 \mathrm{~h}$ at $37^{\circ} \mathrm{C}$ while shaking at $160 \mathrm{rpm} .100$ $\mu \mathrm{L}$ of each well was spread directly on $\mathrm{MH}$ agar dishes for $\mathrm{MBC}$ determination, and a second $100 \mu \mathrm{L}$ aliquot was diluted 1:1000 before spreading on agar for MIC determination, as any optical detection of bacterial growth was impeded by the turbidity of the compound suspensions. The agar dishes were incubated overnight and checked for bacterial colonies. The MIC corresponds to the lowest tested concentration where the bacterial growth did not exceed the starting inoculum of $1 \times 10^{6} \mathrm{cfu} / \mathrm{mL}$. The $\mathrm{MBC}$ is defined as the lowest concentration without visible bacterial growth on the agar dishes. All compounds were tested against at least three independent E. coli cultures.

\section{RESULTS AND DISCUSSION}

Synthesis. The salen-based ligand $\mathrm{H}_{2} \mathrm{~L}$ has been synthesized following the literature procedure ${ }^{36}$ by a straightforward synthetic route involving 2-hydroxy-3-methoxybenzaldehyde (o-vanillin) and ethane-1,2-diamine (Scheme 1).

The ligand system $\left(\mathrm{H}_{2} \mathrm{~L}\right)$ is composed of an imine-based recognition site, $\mathrm{N}_{2} \mathrm{O}_{2}$, typically able to coordinate transition metal ions after deprotonation. This coordination preorganizes the ligand in a $\Omega$-shape and allows the formation of a neutral compound "LM1", providing an additional coordination site, $\mathrm{O}_{2} \mathrm{O}_{2}$. With two phenol and two methoxy groups, the newly generated compartment allows the binding of further metal ions. Throughout this study, $\mathrm{Cu}$ (II) and $\mathrm{Ni}(\mathrm{II})$ metal ions have been used to fit into the $\mathrm{N}_{2} \mathrm{O}_{2}$ cavity of $\mathrm{H}_{2} \mathrm{~L}$, yielding the previously reported $\mathrm{LCu}$ and $\mathrm{LNi}$ complexes, ${ }^{37}$ which were then employed as metallo-ligand for the coordination of additional metal ions. New mixed metal compounds have then been synthesized from $\mathrm{LCu}$ in combination with $\mathrm{Mn}$ (II), $\mathrm{Cu}(\mathrm{II}), \mathrm{Zn}(\mathrm{II})$, or $\mathrm{Bi}(\mathrm{III})$ ions. The previously known 
a)
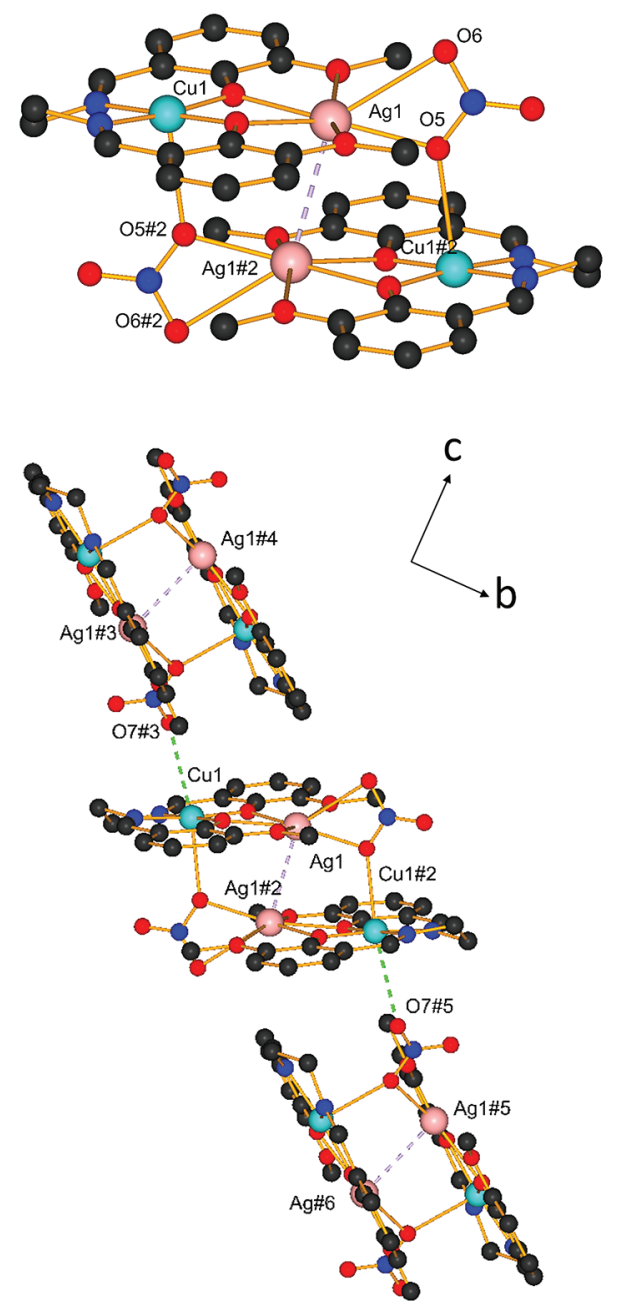

b)
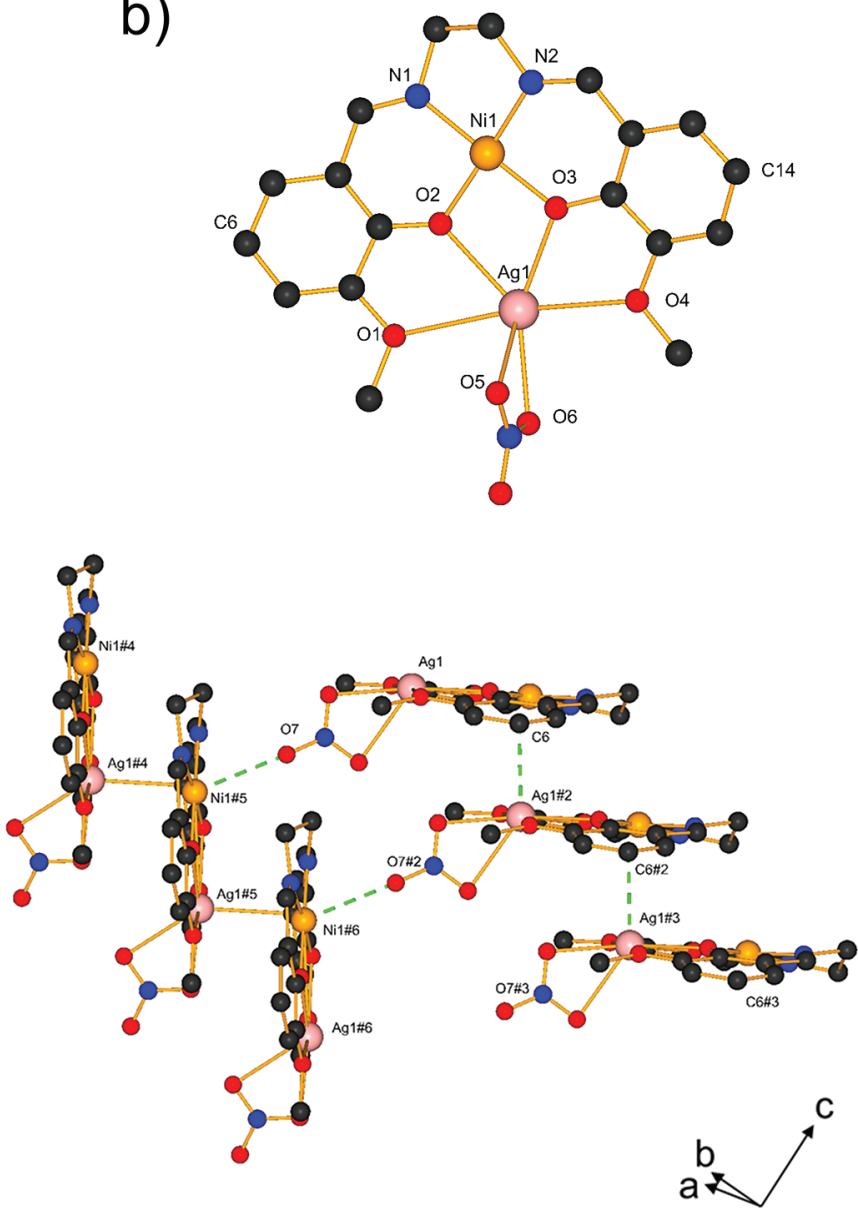

Figure 1. (a) Head-to-tail sandwich type arrangement of the known LCuAg 1 (top left, \#2(1/2-x, 1/2-y, $-z)$ ) showing Cu1-O5 and Ag(I) $\cdots$ $\mathrm{Ag}(\mathrm{I})$ interactions (purple dashed bond) and the packing arrangement (bottom left, \#3(1/2-x, $-1 / 2+y, 1 / 2-z), \# 4(x,-y,-1 / 2+z)$, \#5( $x, 1-y$, $-1 / 2+z)$, \#6(1/2-x, 1/2+y, -1/2-z)) showing Cu1-O7 interactions (green dashed bonds) along the $b$-axis. (b) Crystal structure of the

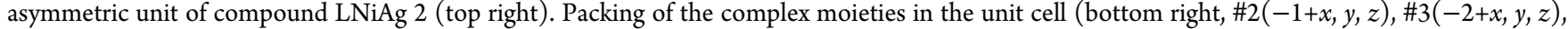
$\# 4(5 / 2-x, 1-y,-1 / 2+z), \# 5(3 / 2-x, 1-y,-1 / 2+z), \# 6(1 / 2-x, 1-y,-1 / 2+z))$ showing the $\mathrm{Ag}(\mathrm{I}) \cdots \mathrm{C} 6$ and $\mathrm{Ni}(\mathrm{II}) \cdots \mathrm{O} 7$ interactions (green dashed bonds, bottom) along the $b$-axis and $c$-axis, respectively. $\mathrm{H}$-atoms are omitted for clarity.

bimetallic copper-silver compound ${ }^{42}$ has also been taken into account during this study, as well as its new nickel analogue for comparison.

Description of the Crystal Structures. In order to explore the coordination mode of the metallo-ligand $\mathrm{LCu}$ with the different metal ions (and LNi with $\mathrm{Ag}(\mathrm{I})$ ), single crystal Xray analysis was performed on all compounds. The crystal structures are described below following the charge of the M2 as well as the ionic radii of the cation, starting thus from $\mathrm{Ag}(\mathrm{I})$ and ending by $\mathrm{Bi}(\mathrm{III})$. $\left[\left\{\mathrm{LCuAg}\left(\mathrm{NO}_{3}\right)\right\}_{2}\right]$ is thereafter abbreviated as "LCuAg" (1) and $\left[\mathrm{LNiAg}\left(\mathrm{NO}_{3}\right)\right]$ as "LNiAg" (2), $\left[\mathrm{LCuMn}\left(\mathrm{NO}_{3}\right)_{2}\right]$ as "LCuMn" (3), $\left[\mathrm{LCuCu}\left(\mathrm{NO}_{3}\right)_{2}\right]$ as "LCuCu" (4), $\left[\mathrm{LCuZn}\left(\mathrm{NO}_{3}\right)_{2}\right]$ as "LCuZn" (5), and $\left[\left\{\mathrm{LCuBi}\left(\mathrm{NO}_{3}\right)_{3}\right\}(\mathrm{ACN})\right]$ as "LCuBi" (6) (Table 1) (bond lengths are gathered in the Supporting Information, Table S3).

Single crystals of the six compounds were obtained from the reaction between $\mathrm{LCu} / \mathrm{LNi}$ with the corresponding metal ion nitrate salt. Each crystal structure reveals a 1:1:1 stoichiometry of the $\mathrm{LM}_{1} \mathrm{M}_{2}$ compound. In each compound, $\mathrm{Cu}(\mathrm{II}) / \mathrm{Ni}$ (II) as $\mathrm{M} 1$ is coordinated in a square planar fashion by the phenolate and imine groups of the $\mathrm{N}_{2} \mathrm{O}_{2}$ chelating site of the ligand, with angle sums close to $360^{\circ}$.

In the already known LCuAg bimetallic compound (1), $\mathrm{Ag}(\mathrm{I})$ is coordinated by all four oxygen atoms of the ligand. ${ }^{42}$ It is found ca. $0.3 \AA$ out of the $\mathrm{Cu}-\mathrm{N}_{2} \mathrm{O}_{2}$ mean plane of the metalloligand and oriented toward the silver ion of an antiparallel neighbor moiety. The silver ion completes its coordination sphere by two $\mathrm{O}$-atoms $\mathrm{O} 5$ and $\mathrm{O} 6$ belonging to one nitrate anion. O5 further coordinates to the copper ion of a neighboring entity; the copper ion thus reaching a bond valence sum of $1.96 .^{42}$ The coordination of $\mathrm{Ag}(\mathrm{I})$ with $\mathrm{LCu}$ leads to dimers by symmetry (inversion center in the middle of the $\operatorname{Ag}(\mathrm{I})-\mathrm{Ag}(\mathrm{I})$ contact) with a head-to-tail sandwich-type arrangement through $\mathrm{Cu} 1-\mathrm{O} 5$ bonds and Ag1 $\cdots \mathrm{Ag} 1$ interactions $(2.516(4) \AA$ and $3.053(7) \AA$, respectively) (Figure 1A). ${ }^{43,44}$

Interestingly, our new compound LNiAg (2) does not present the same structural characteristics as its $\mathrm{Cu}$-analogue. Compound 2 is composed by a $\mathrm{Ni}$ (II) cation coordinated by two O-atoms, $\mathrm{O} 2$ and $\mathrm{O} 3$, and two $\mathrm{N}$-atoms, $\mathrm{N} 1$ and $\mathrm{N} 2$, in a perfect square planar fashion and with a $\mathrm{Ag}(\mathrm{I})$ cation 

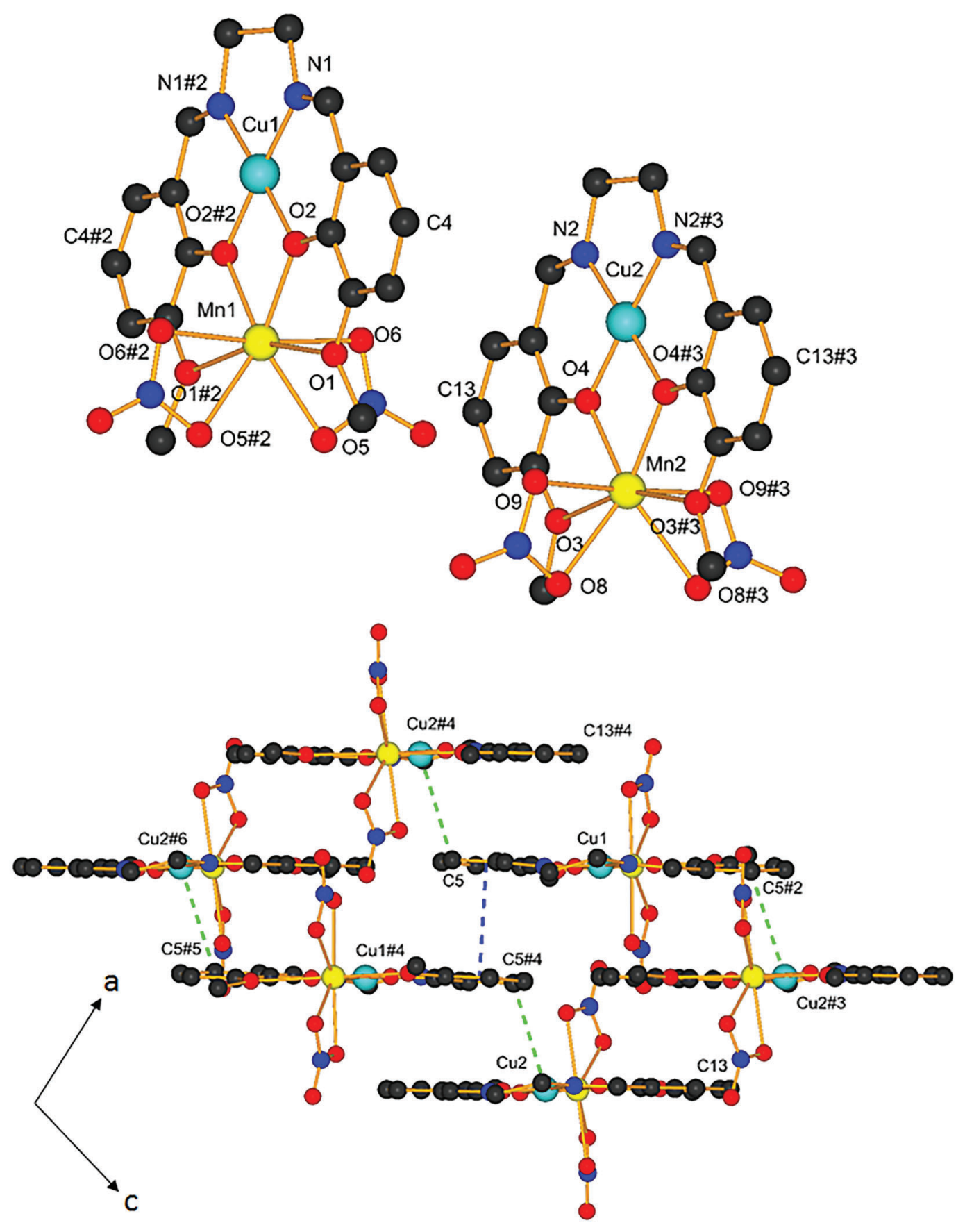

Figure 2. Structure of the two distinct units A (top left) and B (top right) of compound LCuMn 3 (top) and its antiparallel packing (\#2(3/2-x, $y$, $3 / 2-z), \# 3(1-x, 1-y, 1-z), \# 4(1+x, y, z)$, bottom), showing the $\pi-\pi$ interactions (blue dashed bonds) and Cu2 $\cdots \mathrm{C} 5$ interactions (green dashed bonds). H-atoms have been omitted for clarity.

occupying the $\mathrm{O}_{2} \mathrm{O}_{2}$ cavity. The silver cation completes its coordination sphere with two O-atoms, O5-O6, from the nitrate counterion. In contrast to $1, \mathrm{Ni}$ (II) reaches a bond valence sum of 1.99 solely by the $\mathrm{O}_{2} \mathrm{~N}_{2}$ donors and hence does not need to complete its coordination sphere through additional coordination, as already observed in previous studies with alkali metal ions. ${ }^{33}$ This leads to an offset parallel arrangement of the complex moieties into a $1 \mathrm{D}$ coordination polymer along the crystallographic $b$-axis, governed by Ag1C6 interactions of 2.690(1) A. This interaction further leads to a nonplanarity of the ligand, with the two aromatic rings forming an angle of $17.04^{\circ}$. The packing of these $1 \mathrm{D}$ strands in the unit cell is defined by a very weak coordination of the third $\mathrm{O}$-atom of the anion, $\mathrm{O} 7$, to the $\mathrm{Ni}$ (II) with a distance of 3.020(9) A along the crystallographic $c$-axis (Figure 1B).

In compound LCuMn (3), the asymmetric unit is composed of two halves of two distinct complexes, named complex A for the one containing $\mathrm{Cu} 1$, and $\mathrm{B}$ for the one containing $\mathrm{Cu} 2$. The entire units are obtained through a $\mathrm{C}_{2}$ rotation axis running through the $\mathrm{Cu}(\mathrm{II})$ and $\mathrm{Mn}$ (II) ion, in which the $\mathrm{Cu}$ (II) ions are coordinated by the $\mathrm{N}$ and $\mathrm{O}$ atoms of the imine and the phenoxy groups, while the $\mathrm{Mn}(\mathrm{II})$ atoms fit 

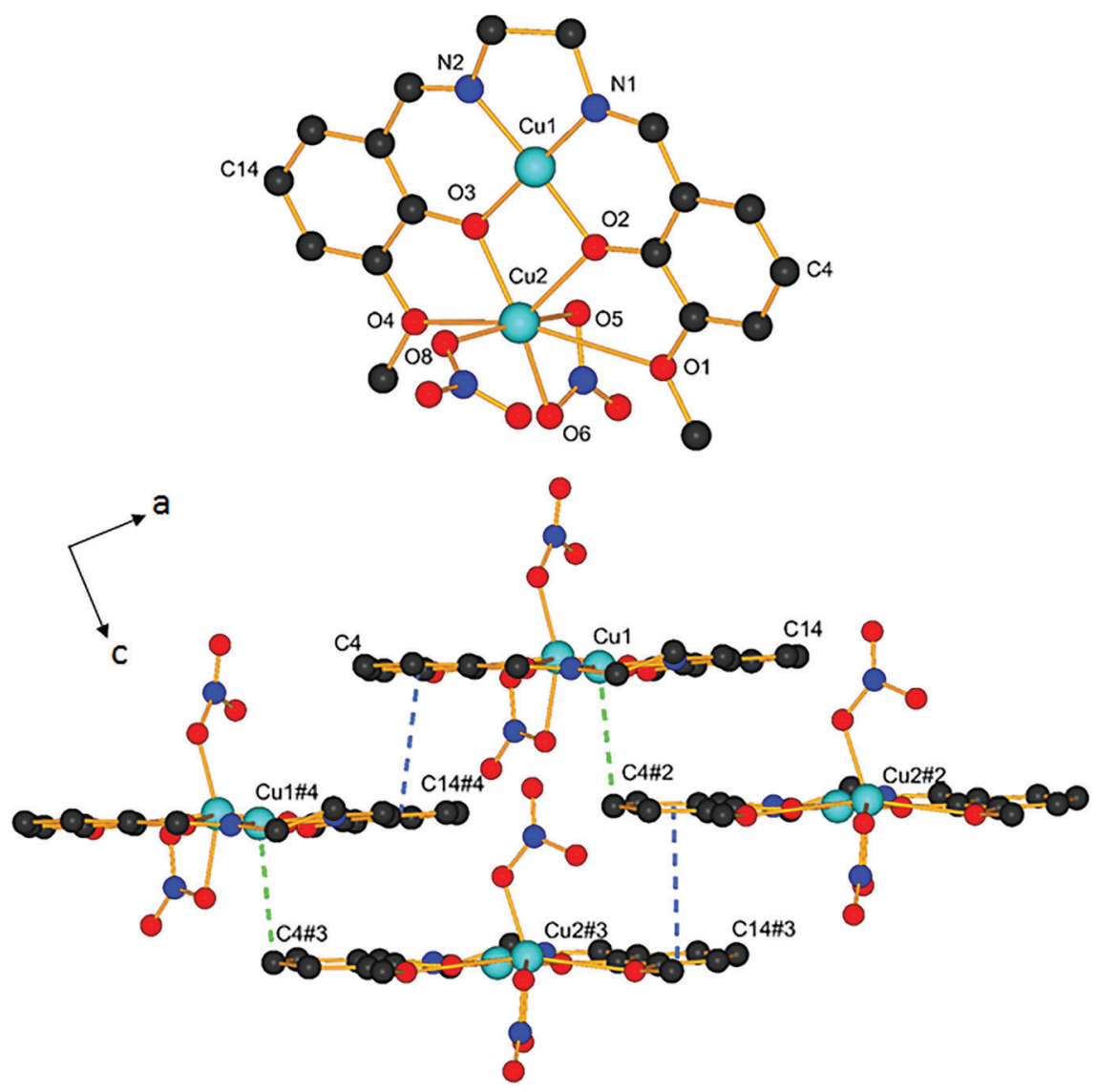

Figure 3. Crystal structure of the asymmetric unit of $\mathrm{LCuCu} 4$ (top) and the antiparallel packing arrangement (bottom, $\# 2(1 / 2+x, 3 / 2-y, 1 / 2+$ $z)$, \#3(-1/2+x, $3 / 2-y, 1 / 2+z)$, \#4 $(-1+x, y, z)$ ) showing the $\pi-\pi$ interactions (blue dashed bonds) and Cu1-C4 interactions (green dashed bonds) along $a$-axis. The minor-occupancy atoms and the H-atoms have been omitted for clarity.

perfectly into the $\mathrm{O}_{2} \mathrm{O}_{2}$ cavity provided by the phenoxy and the methoxy groups. Complex A differs from the B-complex in the coordination of $\mathrm{Mn}(\mathrm{II})$. Thus, $\mathrm{Mn} 1$ in $\mathrm{A}$ is slightly more out of the aromatic plane with a distance of ca. $0.19 \AA$ (compared to ca. $0.04 \AA$ for $\mathrm{Mn} 2$ in the B-complex) and has a longer Mn1-O1 distance to the methoxy group (2.481(7) $\AA$ ) than the equivalent bond in the Cu2-complex ( $\mathrm{Mn} 2-\mathrm{O} 3$ $2.475(6))$. Contrarily, the distance $\mathrm{Mn} 1-\mathrm{O} 2$ distance to the phenoxy group is shorter in A than in B (see Supporting Information). The coordination sphere of the $\mathrm{Mn}$ (II) ions is further completed by four $\mathrm{O}$-atoms of two symmetry equivalent nitrate ions (O5 and $\mathrm{O} 6$ and their symmetry equivalents for $\mathrm{Mn} 1$, and $\mathrm{O} 8$ and $\mathrm{O} 9$ and their symmetry equivalents for $\mathrm{Mn} 2$ ). The $\mathrm{Mn}$-nitrate distances in complex B are longer and more asymmetric than the equivalent distances in complex A. In both LCuMn complexes, the bond valence sum for $\mathrm{Cu}$ (II) is around 1.95, while it is ca. 2 for $\mathrm{Mn}$ (II) in A and 1.96 in $\mathrm{B}$. The packing of these moieties is controlled by $\mathrm{Cu} 1-\mathrm{C} 14, \mathrm{Cu} 2-\mathrm{C} 5$, and $\pi-\pi$ interactions (3.502(8) $\AA$, $3.317(7) \AA$, and $3.497(2) \AA$, respectively) along the crystallographic $c$-axis, leading to alternating antiparallel strands (Figure 2).

After changing the counterions to chloride, perchlorate, and acetate, water-containing compounds were obtained as described in Table S4 and Figures S3-S5.

In compound $\mathrm{LCuCu}(4), \mathrm{Cu} 1$ has the known square planar environment, while the second copper cation $\mathrm{Cu} 2$ is bound by all four $\mathrm{O}$-atoms of the $\mathrm{O}_{2} \mathrm{O}_{2}$ compartment of the metal- loligand $\mathrm{LCu}$. Its coordination sphere is completed by three further $\mathrm{O}$-atoms belonging to two different nitrate anions (O5, O6, and O8) found in the axial positions of a distorted octahedron. One nitrate moiety is on a roughly 50:50 split position (refined at 51.5(9)\% and $48.5(9) \%$ ), and $\mathrm{Cu} 2$ is then connected to O8 with a distance of $1.933(9) \AA$ or to O8A at 1.942(8) A. Compound 4 is not completely planar, as the angle between the two aromatic rings of the ligand of $3.8^{\circ}$ indicates. This slight distortion can be explained by an antiparallel arrangement of the moieties, allowing $\mathrm{Cul}$ to interact with neighboring entities by $\mathrm{Cu} 1-\mathrm{C} 4$ interactions (3.249(2) $\AA$ ), while the opposite aromatic rings stack as well with $\pi-\pi$ interactions of 3.622(2) $\AA$ (ring-center to ring-center) along the crystallographic a-axis (Figure 3 ).

Compound LCuZn (5) adopts a similar structure to 4, with $\mathrm{Zn}(\mathrm{II})$ being perfectly lodged in the $\mathrm{O}_{2} \mathrm{O}_{2}$ cavity. The main difference with $\mathbf{4}$ is that the zinc ion completes its coordination sphere with three $\mathrm{O}$-atoms from two nitrate ions, both adopting two distinct orientations with respective occupancy of $2 / 3$ and $1 / 3$ (refined to $67.8(9) \%$ for the form N3 and N4 and of $32.2(9) \%$ for the form N3A and N4A). The zinc cation is thus bound by $\mathrm{O} 5, \mathrm{O} 6$, and $\mathrm{O} 8$ or by $\mathrm{O} 5 \mathrm{~A}, \mathrm{O} 8 \mathrm{~A}$, and $\mathrm{O} 9 \mathrm{~A}$ depending on the occupancy. The two aromatic rings of the complex entity form an angle of $7.81^{\circ}$, and $\mathrm{LCuZn}$ is thus not completely planar. This effect is probably again induced by an antiparallel arrangement of the moieties, which leads to alternating strands through $\mathrm{Cu} 1-\mathrm{C} 14$ and $\mathrm{Cu} 1-\mathrm{C} 4$ interactions as well as $\pi-\pi$ interactions (3.397(3) Å, 3.463(2) A, 


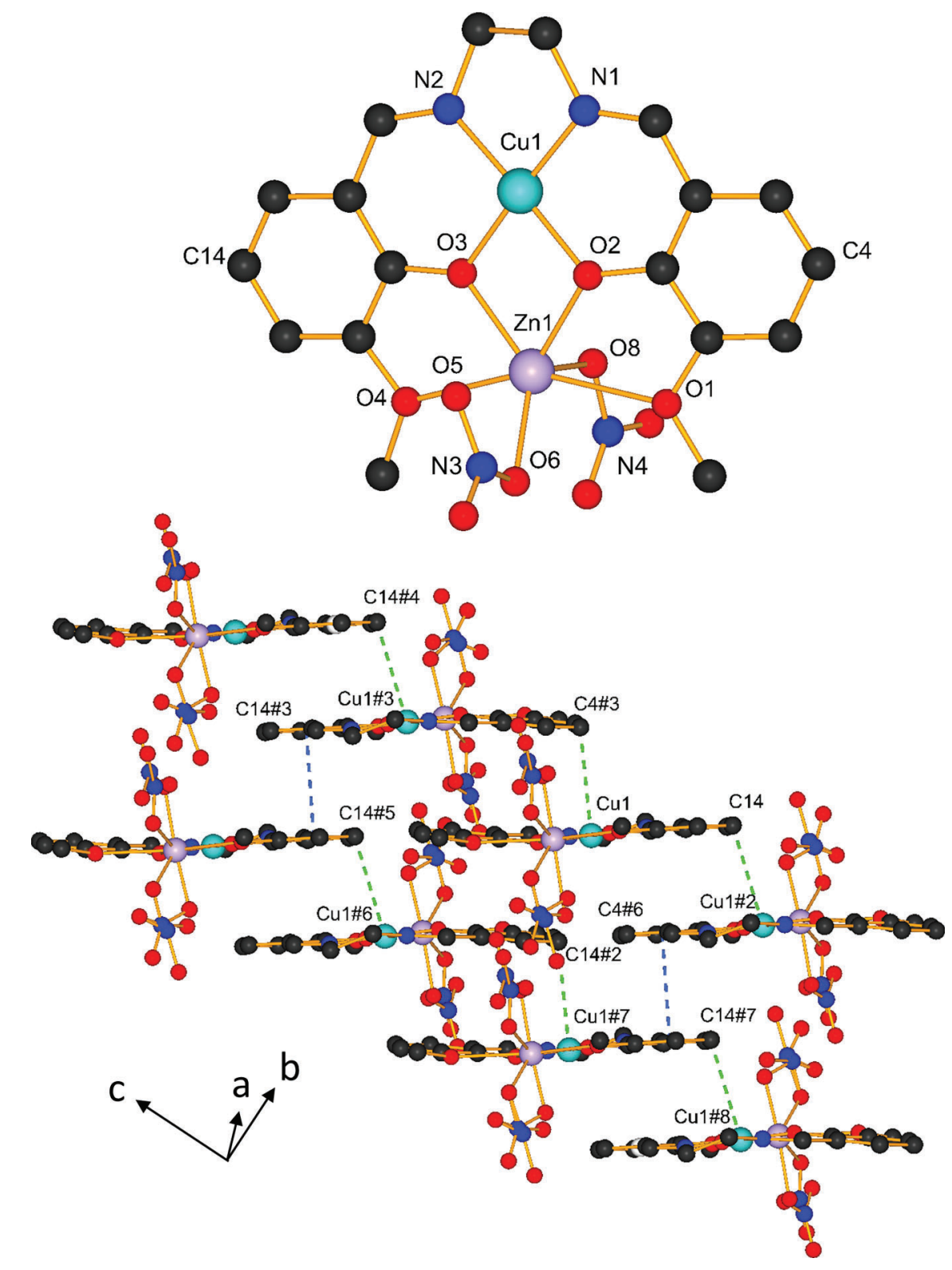

Figure 4. Crystal structure of the asymmetric unit of LCuZn $5(\# 2(1-x, 1-y,-z), \# 3(1-x,-1-y, 1-z), \# 4(x, y, 1+z), \# 5(-1+x, y, 1+z), \# 6(-x$, $1-y, 1-z)$, \#7 (-1+x, y, $z)$, \#8(-x,1-y,-z), top) showing the $\pi-\pi$ interactions (blue dashed bonds, bottom) and $\mathrm{Cu}(\mathrm{II}) \cdots \mathrm{C} 4 / \mathrm{Cu}(\mathrm{II}) \cdots \mathrm{C} 14$ interactions (green dashed bonds, bottom). H-atoms are omitted for clarity.

and $3.500(2) \AA$, respectively) along the crystallographic $c$-axis (Figure 4).

In compound $\mathrm{LCuBi}(6)$, the bismuth ion is coordinated by all four $\mathrm{O}$-atoms of the $\mathrm{O}_{2} \mathrm{O}_{2}$ chelating site of $\mathrm{L}$ and completes its coordination sphere with six oxygen atoms from three different nitrate ions, as it is charged $3+$. Being furthermore much larger than, e.g., $\mathrm{Mn}$ (II) (ionic radii $67 \mathrm{pm}$ for $\mathrm{Mn}(\mathrm{II})$, low spin, and ca. $100 \mathrm{pm}$ for $\left.\mathrm{Bi}(\mathrm{III})^{45}\right), \mathrm{Bi}(\mathrm{III})$ is ca. $0.438 \AA$ out of the $\mathrm{Cu}-\mathrm{N}_{2} \mathrm{O}_{2}$ mean plane, thus disturbing the planarity of the metallo-ligand as evidenced by the angle of $5.16^{\circ}$ between the two aromatic rings of the ligand. This in turn leads to a weaker coordination of the $\mathrm{N}_{2} \mathrm{O}_{2}$ cavity with the $\mathrm{Cu}$ (II), as shown by a lower bond valence sum than in the other compounds, reaching only 1.90. As a consequence, a close interaction between $\mathrm{Cu}(\mathrm{II})$ and $\mathrm{N} 6$ of a solvent molecule of acetonitrile (2.810(2) $\AA$ ) acting as a terminal ligand and $\mathrm{O} 13$ of a nitrate anion $(2.940(2) \AA)$, which acts as bridging ligand between copper and bismuth ions of neighboring entities, is observed. $\mathrm{Cu}$ (II) has thus a distorted octahedral geometry, as expected from the Jahn-Teller effect. Moreover, the elongated bond generated by the nitrate bridging ligand produces then an alternating head-to-tail arrangement of the units along the $b$ axis. This compound features a parallel arrangement based on $\pi-\pi$ interactions between neighbor complex entities along the $a$-axis (Figure 5).

The formation of 1:1:1 complexes (L:M1:M2) is always observed in the solid state. As already observed previously, ${ }^{33}$ LCuM2 with M2, being a third row element, can lead to alternating arrangements of the $\mathrm{LCu}$ entities in order to allow interactions of the $\mathrm{Cu}(\mathrm{II})$ with anions, but also parallel arrangements with $\mathrm{Cu}(\mathrm{II})-\pi$ interactions are observed. For the heavier cations, packing with a head-to-tail arrangement into coordination polymers along the crystallographic $b$-axis is found in the case of $\mathrm{LCuBi}$; discrete antiparallel dimer 

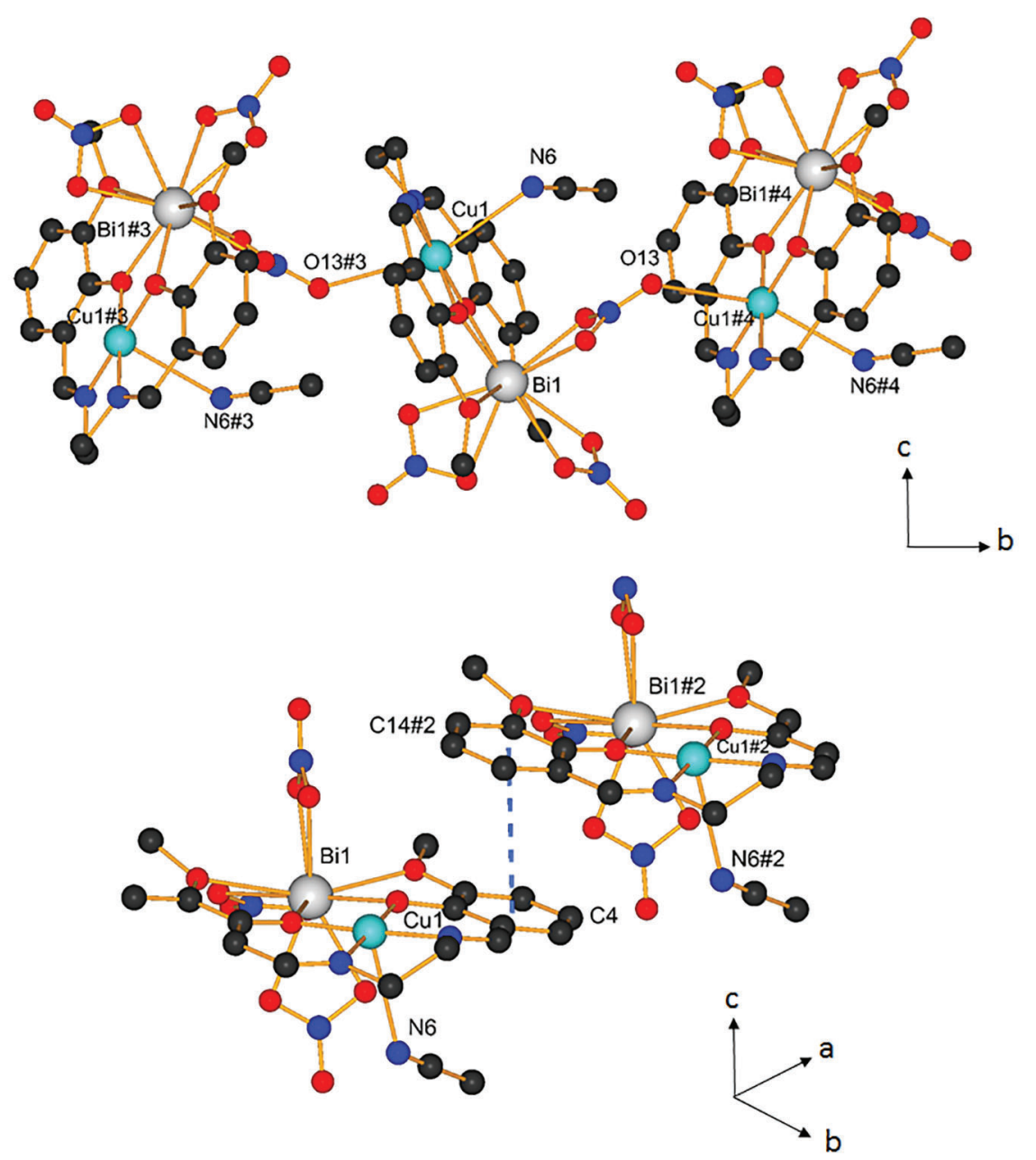

Figure 5. Crystal structure of LCuBi 6 presents an antiparallel head-to-tail arrangement (top, \#3(1-x,1/2+y, 3/2-z), \#4(1-x, $-1 / 2+y, 3 / 2-z)$ ) by $\mathrm{Cu} 1-\mathrm{N} 6$ and $\mathrm{Cu} 1-\mathrm{O} 13$ additional bonds and a parallel arrangement of the complexes (bottom, $\# 2(1-x, 1-y,-z)$ ) through $\pi-\pi$ packing (blue dashed bonds) along the $a$-axis. All $\mathrm{H}$-atoms have been omitted for clarity.
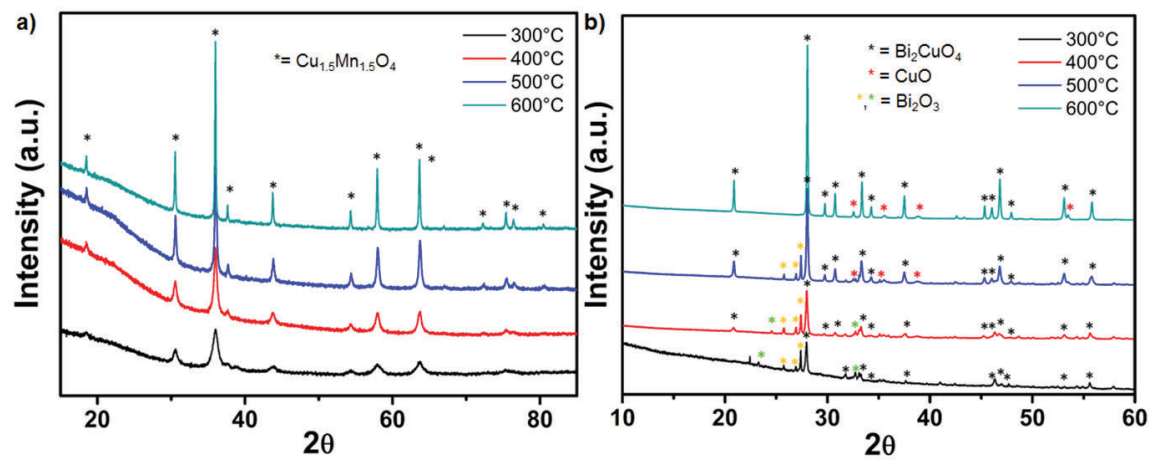

Figure 6. PXRD analysis of (a) LCuMn (3) and (b) LCuBi (6) upon thermal decomposition at 300, 400, 500, and $600{ }^{\circ} \mathrm{C}$.

formation in the case of LCuAg occurs. These results can be explained by the fact that larger cations are slightly pushed out of the $\mathrm{O}_{2} \mathrm{O}_{2}$ plane, distorting the $\mathrm{LCu}$ moiety to a certain extent. This affects the charge compensation (BVS) of the copper ion in the respective $\mathrm{LCu}$ entities, inducing further interactions of the $\mathrm{Cu}$ (II) ions with neighboring anions (in both, $\mathrm{LCuAg}$ and $\mathrm{LCuBi}$ ) and solvent molecule coordination as in the case of LCuBi. This phenomenon is not observed in our $\mathrm{Ni}(\mathrm{II})$-silver analogue (2) where the BVS of the $\mathrm{Ni}(\mathrm{II})$ is close to 2, such that additional bonds to satisfy the coordination of $\mathrm{Ni}(\mathrm{II})$ are not needed.

Precursors for Mixed Metal Oxides. As mentioned in the Introduction, we are particularly interested here in the generation of mixed metal oxides and antimicrobial properties for the specific series of compounds presented here. For the LCuMn (3) and LCuBi (6) compounds, mixed metal oxides can be of interest, as copper-manganese oxides showed promising properties as selective absorber coatings for solar applications $^{46}$ and exhibited efficient catalytic activity for $\mathrm{CO}$ 


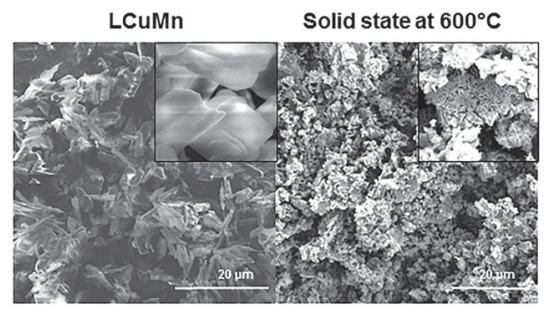

LCuMncombustions

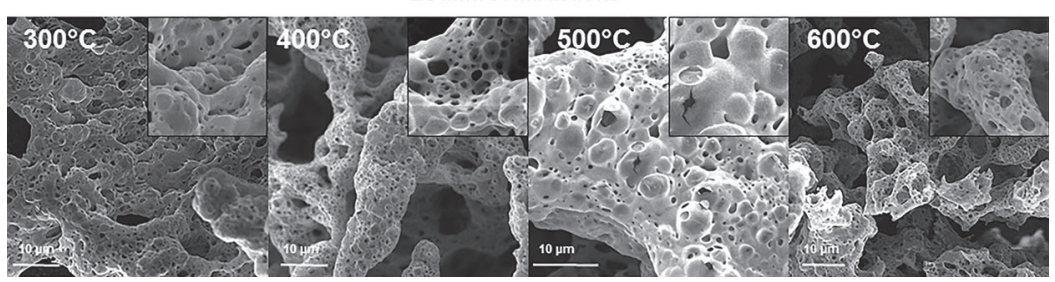

Figure 7. SEM images (with a zoom at $2 \mu \mathrm{m}$ ) of LCuMn (3) (top, left) and the mixture of $\mathrm{Cu}\left(\mathrm{NO}_{3}\right)_{2}$ and $\mathrm{Mn}\left(\mathrm{NO}_{3}\right)_{2}$ after the thermal decomposition (top, right), as well as SEM images of samples of LCuMn after the thermal decomposition at 300, 400 , 500, and $600{ }^{\circ} \mathrm{C}$ for $4 \mathrm{~h}$ (bottom).

oxidation at ambient temperature, ${ }^{35}$ while copper and bismuth containing oxides were investigated for their optical, ${ }^{47}$ conductive, $^{34}$ and magnetic ${ }^{48}$ properties, and as catalyst for organic pollutants. ${ }^{48,49} \mathrm{We}$ therefore tested the compounds LCuMn (3) and LCuBi (6), in which the metal ions are already prearranged in close proximity, as single-source precursors for these mixed metal oxides at different temperatures, following the evolution of the morphology and microstructure of the oxides.

For LCuMn (3), the TGA displayed a one-step decomposition process starting at around $300{ }^{\circ} \mathrm{C}$ that is completed at approximately $400{ }^{\circ} \mathrm{C}$ at a heating speed of $5{ }^{\circ} \mathrm{C} / \mathrm{min}$ (Figure S1). The total observed weight loss of $71.7 \%$ could be matched with the decomposition of the organic ligand and the nitrate moieties, with the expected value for that being a weight loss of $72 \%$.

Powder X-ray diffraction studies demonstrated that the pyrolysis of 3 leads to polycrystalline, spinel-type $\mathrm{Cu}_{1.5} \mathrm{Mn}_{1.5} \mathrm{O}_{4}$ as the only crystalline phase (100\%) at all tested temperatures. $\mathrm{Cu}_{1.5} \mathrm{Mn}_{1.5} \mathrm{O}_{4}$ belongs to the oxide family of the composition of $\mathrm{Cu}_{x} \mathrm{Mn}_{3-x} \mathrm{O}_{4}(x=1.5)$ and has the copper ion coordinated by four $\mathrm{O}$-atoms in a tetrahedral fashion, while the manganese has a distorted octahedral environment. ${ }^{50}$ As hoped for, the stoichiometry of the final oxide corresponds to the metal ion ratio present in the molecular precursor (Figure 6a), and the distances in the final $\mathrm{Cu}_{1.5} \mathrm{Mn}_{1.5} \mathrm{O}_{4}$ of $\mathrm{Cu}-\mathrm{O}$ and $\mathrm{Mn}-\mathrm{O}$ are 2.0989 and $1.9166 \AA$, respectively, similar to the distances found in compound $3 .^{51}$ An increase of the peak intensities and narrowing of their widths was observed gradually as the combustion temperature increased, giving an increasing average crystallite size from $13.5 \mathrm{~nm}$ at $300{ }^{\circ} \mathrm{C}$ to $125 \mathrm{~nm}$ at $600{ }^{\circ} \mathrm{C}$ (Table S1). The surface morphologies of all samples $\left(300,400,500\right.$, and $600{ }^{\circ} \mathrm{C}$ ) exhibited a porous, foam-like 3Dnetwork composed of multiple pores and channels, likely induced by the gas release during the pyrolysis of 3 (Figure 7). The $\mathrm{N}_{2}$ adsorption-desorption analysis (Table 2) demonstrated that the calcination product of LCuMn (3) at $300{ }^{\circ} \mathrm{C}$ possesses the largest specific surface area and pore volume which both decreased with increasing combustion temperature. These results are in agreement with the increase of the crystallite sizes obtained as temperature increased.
Table 2. Surface Area and Cumulative Pore Volume Measurements at Different Temperatures

\begin{tabular}{|c|c|c|}
\hline \multicolumn{3}{|c|}{ For Compound LCuMn (3) } \\
\hline $\begin{array}{l}\text { Calcination } \\
\text { temperature }\end{array}$ & $\begin{array}{l}\text { Surface area, } S_{\mathrm{BET}} \\
{\left[\mathrm{m}^{2} / \mathrm{g}\right]}\end{array}$ & $\begin{array}{c}\text { Cumulative pore volume, } V_{\mathrm{BJH}} \\
{\left[\mathrm{cm}^{3} / \mathrm{g}\right]}\end{array}$ \\
\hline $300{ }^{\circ} \mathrm{C}$ & 35 & 0.14 \\
\hline $400{ }^{\circ} \mathrm{C}$ & 21 & 0.12 \\
\hline $500{ }^{\circ} \mathrm{C}$ & 16 & 0.10 \\
\hline $600{ }^{\circ} \mathrm{C}$ & 5 & 0.02 \\
\hline \multicolumn{3}{|c|}{ For compound $\mathrm{LCuBi}(6)$} \\
\hline $\begin{array}{l}\text { Calcination } \\
\text { temperature }\end{array}$ & $\begin{array}{l}\text { Surface area, } S_{\mathrm{BET}} \\
{\left[\left[\mathrm{m}^{2} / \mathrm{g}\right]\right.}\end{array}$ & $\begin{array}{c}\text { Cumulative pore volume, } \mathrm{V}_{\mathrm{BJH}} \\
{\left[\mathrm{cm}^{3} / \mathrm{g}\right]}\end{array}$ \\
\hline $600{ }^{\circ} \mathrm{C}$ & 2 & 0.006 \\
\hline
\end{tabular}

Interestingly, and in order to compare our precursor with this classical synthesis method, heating a ball-milled 1:1 $\mathrm{Cu}\left(\mathrm{NO}_{3}\right)_{2} / \mathrm{Mn}\left(\mathrm{NO}_{3}\right)_{2}$ mixture to $600{ }^{\circ} \mathrm{C}$ led to a mixture of $\mathrm{CuO}$ and the spinel-like $\mathrm{CuMn}_{2} \mathrm{O}_{4}$ phase $\left(\mathrm{Cu}_{x} \mathrm{Mn}_{3-x} \mathrm{O}_{4}\right.$, copper content $x=1$ ) with crystallite sizes of $58 \mathrm{~nm}$. The SEM images of this sample showed the aggregation of irregular particles. Hence, the $\mathrm{Cu}_{1.5} \mathrm{Mn}_{1.5} \mathrm{O}_{4}$ cannot be produced under such mild conditions starting from simple precursors. Indeed, traditionally, the spinel-type oxides $\mathrm{Cu}_{1.5} \mathrm{Mn}_{1.5} \mathrm{O}_{4}$ and $\mathrm{CuMn}_{2} \mathrm{O}_{4}$ are prepared from oxides or carbonates of copper and manganese in solid state reactions at around $900{ }^{\circ} \mathrm{C}$ during $24 \mathrm{~h}^{52}$ Hence, using the precursor 3 clearly presents an advantage for the low-temperature generation of nanoscale $\mathrm{Cu}_{1.5} \mathrm{Mn}_{1.5} \mathrm{O}_{4}$.

For LCuBi (6), the TGA measurement showed that a first mass loss of $2.4 \%$ beginning at approximately $100{ }^{\circ} \mathrm{C}$ is observed that correlates with the loss of residual acetonitrile. The further decomposition behavior of $\mathrm{LCuBi}$ is different from LCuMn and starts at around $150{ }^{\circ} \mathrm{C}$ with three consecutive weight losses representing approximately a total of $35.5 \%$ : $9 \%$ correspond to one $\mathrm{NO}_{3}$ at $150{ }^{\circ} \mathrm{C}, 13 \%$ correspond to two $\mathrm{NO}_{3}$ at $200{ }^{\circ} \mathrm{C}$, and $13.5 \%$ are part of the organic ligand, occurring at $300{ }^{\circ} \mathrm{C}$. To sum up, this does not correspond to the expected total decomposition of the organic material which would be on the order of $60 \%$ weight loss (Figure S2). The PXRD analysis of the powders obtained from compound annealing at different temperatures revealed the formation of 


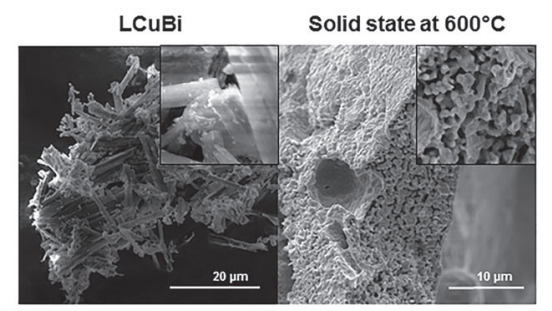

LCuBi combustions

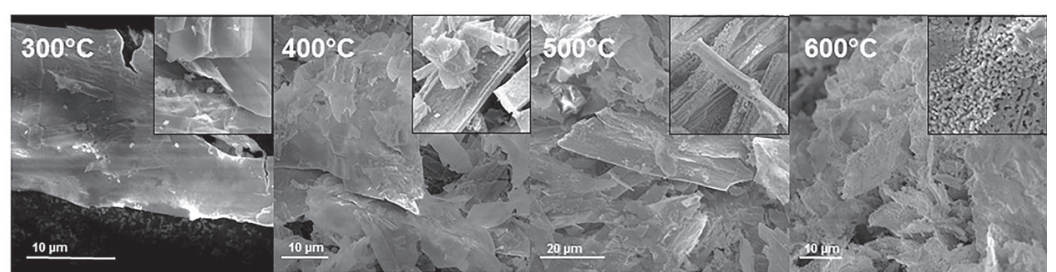

Figure 8. SEM images (with a zoom at $2 \mu \mathrm{m}$ ) of the ligand $\mathrm{LCuBi}(6)$ (top, left) and the mixture of $\mathrm{Cu}\left(\mathrm{NO}_{3}\right)_{2}$ and $\mathrm{Bi}\left(\mathrm{NO}_{3}\right)_{3}$ after the thermal decomposition (top, right) as well as SEM images of samples of LCuBi after the thermal decomposition at $300,400,500$, and $600{ }^{\circ} \mathrm{C}$ (bottom).

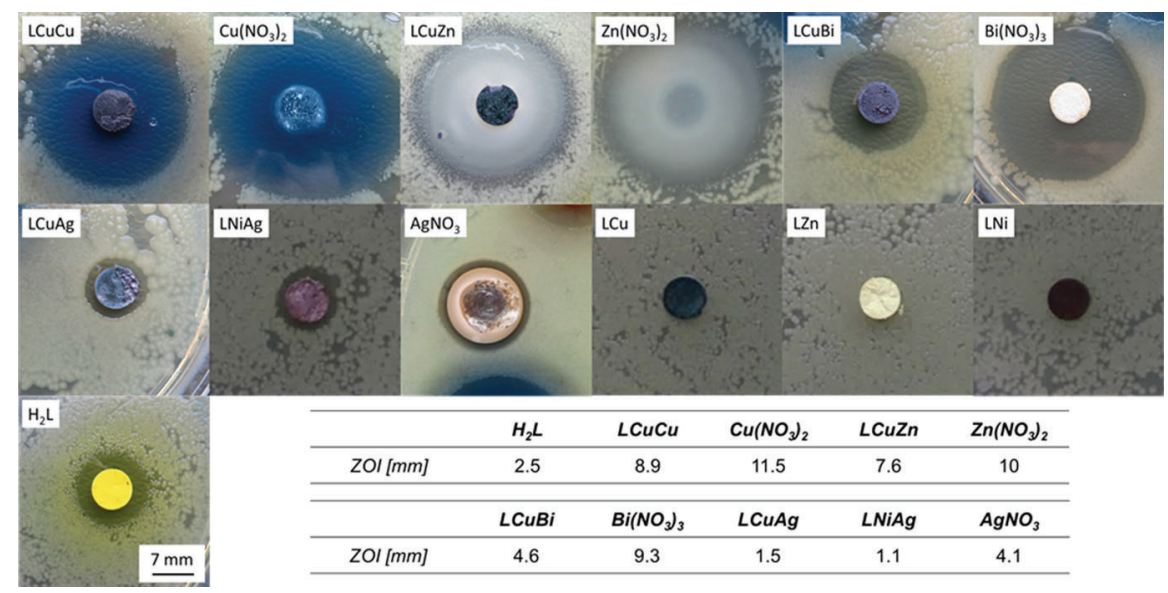

Figure 9. Antimicrobial activity against E. coli of different mono- and bimetallic compounds of the ligand $\mathrm{H}_{2} \mathrm{~L}$ and the respective controls (nitrate salts and ligand alone) by agar diffusion assay. All compounds were used in form of pressed pellets containing $0.05-0.06 \mathrm{mmol}$. The table shows the radii of the inhibition zones (ZOI) in mm measured from the edge of the pellet to the beginning of the bacterial growth.

the $\mathrm{BiCu}_{2} \mathrm{O}_{4}$ phase, but also of $\mathrm{Bi}_{2} \mathrm{O}_{3}, \mathrm{CuO}$, and amorphous material in different proportions depending on the combustion temperature (Figure 6b). The intensity of the peaks corresponding to the mixed metal oxide phase increases progressively with the temperature, reflecting an increase of its purity. The combustion at $300{ }^{\circ} \mathrm{C}$ yields the tetragonal $\mathrm{CuBi}_{2} \mathrm{O}_{4}$ spinel-type structure only in $53 \%$ (together with amorphous material and $\mathrm{Bi}_{2} \mathrm{O}_{3}$ ), whereas at $600{ }^{\circ} \mathrm{C}$ it is obtained as the principal crystalline phase with $\mathrm{CuO}$ detectable in ca. $4 \%$ relative abundance (Table S2). While the starting material contains a $1: 1$ ratio of $\mathrm{Cu}: \mathrm{Bi}$, the final identified mixed metal oxide has a ratio of $1: 2$, explaining the simultaneous formation of copper oxide. The crystallite sizes estimated with the Scherrer equation ranged from 90 to $430 \mathrm{~nm}$, increasing with temperature as already observed for the combustion of LCuMn (3). The stoichiometry of the mixed metal material and the ratio of the phases observed upon combustion of the bimetallic precursor $\mathrm{LCuBi}$ (6) correspond to the published binary phase diagrams of this system, in which the $\mathrm{CuBi}_{2} \mathrm{O}_{4}$ oxide is the only stable ternary phase. ${ }^{53}$

The SEM images of the samples annealed at different temperatures displayed leaf-like 2D nanosheets with various sizes depending on the temperature. Gradually, as the crystallites grow with temperature, they separate from each other, revealing a lace-like surface, which might be due to the fact that two different phases are formed in this process (Figure 8).

The spinel-type $\mathrm{CuBi}_{2} \mathrm{O}_{4}$ material (with the corresponding valences $\mathrm{Cu}^{2+}$ and $\mathrm{Bi}^{3+}$ ) is usually synthesized by a solid state reaction or a hydrothermal process, both involving stoichiometric proportions of $\mathrm{CuO}$ and $\mathrm{Bi}_{2} \mathrm{O}_{3}$ at $973 \mathrm{~K}$ for $24 \mathrm{~h}$ in $\mathrm{air}^{53}$ and producing mostly spherical nanoparticle morphology. ${ }^{54}$ In contrast, the pyrolysis of the $\mathrm{Cu}\left(\mathrm{NO}_{3}\right)_{2} / \mathrm{Bi}\left(\mathrm{NO}_{3}\right)_{3}$ mixture at $600{ }^{\circ} \mathrm{C}$ led to the formation of a mixture of $\mathrm{CuBi}_{2} \mathrm{O}_{4}$ (crystallite size $90 \mathrm{~nm}$ ) and two different $\mathrm{Bi}_{2} \mathrm{O}_{3}$ phases. The SEM image of this combination shows aggregated nanoparticles. For precursor 6, the advantage of using a single source compound is not as evident as for compound 3 , but still allows one to obtain a quite pure spinel phase at $600{ }^{\circ} \mathrm{C}$, bringing down the synthesis temperature by ca. $300{ }^{\circ} \mathrm{C}$.

These studies showed that the use of our new compound LCuMn 3 and, to a lesser extent, $\mathrm{LCuBi}$ 6, as single-source precursors afforded the expected mixed metal oxides, avoiding the formation of carbonates upon combustion in air. The compounds decompose gradually, generating (neat) nanoscale bimetallic oxides under mild conditions and exhibiting 
Table 4. Antimicrobial Active Concentrations for the LCu Complexes Coordinating Another Antimicrobial Active Metal Ion M2 by Broth Microdilution ${ }^{a}$

\begin{tabular}{|c|c|c|c|c|c|c|c|c|}
\hline & $\mathrm{LCuCu}$ & $\mathrm{Cu}\left(\mathrm{NO}_{3}\right)_{2}$ & $\mathrm{LCuZn}$ & $\mathrm{Zn}\left(\mathrm{NO}_{3}\right)_{2}$ & $\mathrm{LCuBi}$ & $\mathrm{Bi}\left(\mathrm{NO}_{3}\right)_{3}$ & $\mathrm{LCuAg}$ & $\mathrm{AgNO}_{3}$ \\
\hline $\mathrm{MIC}[\mathrm{mM}]$ & 6 & $5.3-7.9$ & 2 & 2 & 7 & 7 & 0.03 & $0.04-0.08$ \\
\hline $\mathrm{MBC}[\mathrm{mM}]$ & 12 & $7.9-10.1$ & 4.5 & 3 & 11 & 12.5 & 0.04 & $0.04-0.08$ \\
\hline
\end{tabular}

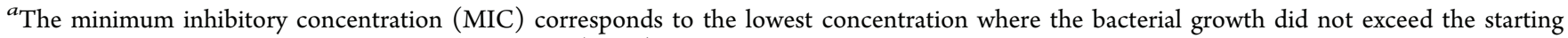
inoculum. The minimum bactericidal concentration (MBC) is defined as the lowest concentration without visible bacterial growth on the agar dishes. The concentrations represent the middle concentration out of three independent experiments performed in duplicates.

evolutive morphologies together with the increase of the temperature when compared to solid state synthetic routes.

Antimicrobial Properties. Based on the fact that silver, copper, zinc, and bismuth possess antimicrobial properties, ${ }^{55}$ the compounds $\mathrm{LCuAg}$ (1) and $\mathrm{LNiAg}(2), \mathrm{LCuCu}$ (4), LCuZn (5), and LCuBi (6) were studied for their antibacterial potential. As reference materials, the ligand $\mathrm{H}_{2} \mathrm{~L}$, the monometallic complexes $\mathrm{LCu}, \mathrm{LNi}$, and $\mathrm{LZn},{ }^{37,38}$ as well as the simple metal nitrate salts were investigated for comparison and as negative and positive controls. In first experiments, the compounds were tested in an agar diffusion assay by placing pressed pellets of the same molar amounts $(0.05 \mathrm{mmol})$ of compound on agar dishes spread with a $1 \times 10^{6} \mathrm{cfu} / \mathrm{mL}$ Escherichia coli 25922 (E. coli) culture. After 24 h, a small zone of inhibition (ZOI) was perceived for the protonated ligand alone, while the monometallic complexes $\mathrm{LCu}, \mathrm{LZn}$, and $\mathrm{LNi}$ did not induce any bactericidal effect. Large inhibition zones were observed for the bimetallic compounds and the nitrate salts, proving a strong antimicrobial activity (Figure 9). The size of the ZOI decreased in the order $\mathrm{LCuCu}>\mathrm{LCuZn}>$ $\mathrm{LCuBi}>\mathrm{LCuAg}>\mathrm{LNiAg}$, with the same order found for the nitrate salts. For all the different metal ions, the inhibition zone of the nitrate salt was slightly larger than that for the respective compound.

These observations might be explained by the fact that the compounds $\mathrm{LCu}, \mathrm{LNi}$, and $\mathrm{LZn}$ are overall neutral with an organic shell, and thus highly insoluble in aqueous media. The square planar M1 ions in LM1 could at best accommodate solvent molecules as axial ligands, which is likely not sufficient to render the complexes soluble, hence they do not diffuse on the agar plate. The second metal ion M2 induces an additional charge to the LM1 complex, giving, depending on M2, $[\mathrm{LM} 1 \mathrm{M} 2]^{+/ 2+/ 3+}$. This charge is compensated by rather loosely bound nitrate anions. Compared to the free metal nitrates, the coordination with the ligand seems to reduce the bioavailability of the coordinated metal ions M1, while keeping the second metal ion M2 still antimicrobially active. Indeed, the blue diffusion halo around $\mathrm{LCuCu}$ indicates the presence of hydrated $\mathrm{Cu}$ (II) ions, whereas this is not at all observed for $\mathrm{LCu}$ alone. Similarly, LCuZn shows a colorless halo and LCuBi a yellow halo that resembles the one seen in zinc and bismuth nitrate, respectively. The fact that $\mathrm{LCuAg}$ and $\mathrm{LNiAg}$ have a low effect in this test might be because such agars for growing bacteria typically contain $\mathrm{NaCl}(5 \mathrm{~g} / \mathrm{L})$, and hence insoluble $\mathrm{AgCl}$ is likely to be formed. This is confirmed by the pellet of $\mathrm{AgNO}_{3}$ around which a brownish precipitate is visible after 24 h.

In order to determine their minimum bactericidal concentration, the bimetallic compounds LCuAg (1), LNiAg (2), $\mathrm{LCuCu}(4), \mathrm{LCuZn}(5)$, and $\mathrm{LCuBi}$ (6) were suspended as powders by sonication in the bacterial growth medium $(\mathrm{MH}$ broth) and diluted to create a concentration series that was then inoculated with $E$. coli at a final inoculum of $1 \times 10^{6} \mathrm{cfu} /$
$\mathrm{mL}$. The antimicrobial effect was determined by taking aliquots after $24 \mathrm{~h}$ of incubation and spreading them for bacterial count on agar plates after another incubation time. All compounds were tested in duplicate against at least three independent $E$. coli cultures. Table 4 comprises the active concentration ranges for the compounds and nitrate salts for comparison. Again, the antimicrobial efficacy is similar for the bimetallic compounds and their respective nitrate salts of $\mathrm{M} 2$, but contrary to the agar diffusion test, the silver compounds were the most active followed by $\mathrm{Cu}(\mathrm{II}), \mathrm{Zn}(\mathrm{II})$, and $\mathrm{Bi}(\mathrm{III})$. The bactericidal concentrations of the $\operatorname{Ag}(\mathrm{I})$ compounds were found to be 2 orders of magnitude lower than for the other compounds or salts, which is in good correspondence to the minimum inhibitory or bactericidal concentrations found in the literature $\left(\mathrm{MICs}^{24} 0.06 \mathrm{mM} \mathrm{Ag}(\mathrm{I})\right.$ versus $2 \mathrm{mM} \mathrm{Zn}(\mathrm{II})$ and $4 \mathrm{mM}$ $\mathrm{Cu}(\mathrm{II})$ ) (Table 4). This can be explained by the fact that the $\mathrm{MH}$ broth does not contain chloride additives; hence, no $\mathrm{AgCl}$ is formed during these measurements, and the silver ion can act as an excellent antimicrobial agent, as shown for other silver compounds previously. ${ }^{56}$

Overall, the envisaged synergistic effect of the two coordinated metal ions could not be confirmed by the performed tests, but nevertheless, a strong antimicrobial activity could be observed for the all compounds in the same extent as also shown for the respective nitrate salts. These results confirm that the salen-type ligand $\mathrm{L}$ is a strong binder for $\mathrm{Cu}(\mathrm{II})$ and that $\mathrm{LCu}$ by itself is not active, although the ligand itself and $\mathrm{Cu}\left(\mathrm{NO}_{3}\right)_{2}$ are both antimicrobial. The second metal ion M2, however, is more loosely bound, as exemplified by the longer $\mathrm{M} 2-\mathrm{O}$ bonds (as compared to $\mathrm{M} 1-\mathrm{O} / \mathrm{N}$, due to the fact that $\mathrm{LCu}$ acts as a neutral ligand toward M2) and can be easily released in biological media where biomolecules can act as competing ligands. Although the initial goals of detecting synergic effects could not be achieved, these results can nevertheless contribute to the elaboration of salen-based surface anchors allowing the immobilization of bioactive metal ions for the design of antimicrobial surfaces. In this respect, future studies should include a long-term investigation of the ion release and stability of the ligand system and the antibacterial properties under biologically relevant conditions, and also of the cytocompatibility with eukaryotic cells.

\section{CONCLUSION}

In this study, five new bimetallic compounds have been synthesized and their structural arrangements have been studied in the solid state, showing the formation of $1: 1$ compounds $\left(\mathrm{LCu}: \mathrm{M}_{2}\right)$. Moreover, their properties as oxide precursors and as antimicrobial agents have been investigated. The heterometallic compounds LCuMn and LCuBi have been used as single-source precursors (SSP) to successfully synthesize mixed metal oxides $\mathrm{CuBi}_{2} \mathrm{O}_{4}$ and $\mathrm{Cu}_{1.5} \mathrm{Mn}_{1.5} \mathrm{O}_{4}$ in good yields and at lower temperatures than in classic solidstate syntheses, excluding the formation of carbonates upon 
combustion in air. Nanoscale materials with different particle sizes were obtained as a function of the temperature. We are now working on further substitutions of the ligand in order to accommodate three different metal ions.

Based on the well-known biocidal activities of some of the chosen metal ions, the bimetallic compounds $\mathrm{LCuAg}, \mathrm{LNiCu}$, $\mathrm{LCuCu}, \mathrm{LCuZn}$, and $\mathrm{LCuBi}$ were investigated for their antimicrobial properties. Tests against E. coli cultures showed a strong antimicrobial activity, suggesting the release of the second metal ion $\mathrm{M}_{2}$, and conferring them interesting antimicrobial effects. The relative antimicrobial effects depended furthermore on the performed test, i.e., agar diffusion versus solution. These exciting results can lead to the creation of salen-based compounds that are attachable to specific surfaces for the binding of bioactive metal ions in order to open therapeutic windows with the elaboration of new biocidal surfaces.

This research enriches the vast chemistry of salen-type compounds, offering new bimetallic structures with exciting properties and providing further insight for the design of new compartmental ligands and their wide range of applications.

\section{ASSOCIATED CONTENT}

\section{(s) Supporting Information}

The Supporting Information is available free of charge at https://pubs.acs.org/doi/10.1021/acs.cgd.9b01610.

General; Synthesis procedure of $\mathrm{H}_{2} \mathrm{~L}$ and $\mathrm{LCu}$ compounds; TGA analysis of compound 3 and 6; Crystallographic data; Additional structures; XPRD of complexes 2-6 (PDF)

\section{Accession Codes}

CCDC 1860979-1860983, 1861004-1861006, and 1861009 contain the supplementary crystallographic data for this paper. These data can be obtained free of charge via www.ccdc.cam.ac.uk/data_request/cif, or by emailing data_request@ccdc. cam.ac.uk, or by contacting The Cambridge Crystallographic Data Centre, 12 Union Road, Cambridge CB2 1EZ, UK; fax: +44 1223336033 .

\section{AUTHOR INFORMATION}

\section{Corresponding Author}

Katharina M. Fromm - Department of Chemistry, University of Fribourg, 1700 Fribourg, Switzerland; 10 orcid.org/00000002-1168-0123; Email: katharina.fromm@unifr.ch

\section{Authors}

Alba Finelli - Department of Chemistry, University of Fribourg, 1700 Fribourg, Switzerland; (i) orcid.org/0000-0002-02739613

Sarah-Luise Abram - Department of Chemistry, University of Fribourg, 1700 Fribourg, Switzerland; 이잉.org/00000001-8555-9898

Nelly Hérault - Department of Chemistry, University of Fribourg, 1700 Fribourg, Switzerland; O orcid.org/00000001-8986-7759

Aurélien Crochet - FriMat, Department of Chemistry, University of Fribourg, 1700 Fribourg, Switzerland; (1) orcid.org/0000-0002-4763-2764

Complete contact information is available at: https://pubs.acs.org/10.1021/acs.cgd.9b01610
Notes

The authors declare no competing financial interest.

\section{ACKNOWLEDGMENTS}

This work was supported by the Swiss National Science Foundation (grant number 200020_152777), by the Fribourg Center for Nanomaterials FriMat, the NCCR Bioinspired Materials, and the University of Fribourg.

\section{REFERENCES}

(1) Lehn, J.-M. Toward Self-Organization and Complex Matter. Science 2002, 295, 2400-2403.

(2) Sharma, S. S.; Dietz, K.; Mimura, T. Vacuolar Compartmentalization as Indispensable Component of Heavy Metal Detoxification in Plants. Plant, Cell Environ. 2016, 39, 1112-1126.

(3) Akine, S.; Matsumoto, T.; Nabeshima, T. Overcoming Statistical Complexity: Selective Coordination of Three Different Metal Ions to a Ligand with Three Different Coordination Sites. Angew. Chem., Int. Ed. 2016, 55, 960-964.

(4) Wezenberg, S. J.; Kleij, A. W. Material Applications for Salen Frameworks. Angew. Chem., Int. Ed. 2008, 47, 2354-2364.

(5) Datta, A.; Das, K.; Massera, C.; Clegg, J. K.; Sinha, C.; Huang, J.H.; Garribba, E. A Mixed Valent Heterometallic $\mathrm{Cu}^{\mathrm{II}} / \mathrm{Na}^{\mathrm{I}}$ Coordination Polymer with Sodium-phenyl Bonds. Dalt. Trans. 2014, 43, 5558-5563.

(6) Gschwind, F.; Crochet, A.; Maudez, W.; Fromm, K. M. From Alkaline Earth Ion Aggregates via Transition Metal Coordination Polymer Networks towards Heterometallic Single Source Precursors for Oxidic Materials. Chimia 2010, 64, 299-302.

(7) Frischmann, P. D.; MacLachlan, M. J. Metallocavitands: An Emerging Class of Functional Multimetallic Host Molecules. Chem. Soc. Rev. 2013, 42, 871-890.

(8) Knizhnik, A.; Shter, G. E.; Grader, G. S.; Reisner, G. M.; Eckstein, Y. Interrelation of Preparation Conditions, Morphology, Chemical Reactivity and Homogeneity of Ceramic YBCO. Phys. C 2003, 400, 25-35.

(9) Andruh, M. The Exceptionally Rich Coordination Chemistry Generated by Schiff-Base Ligands Derived from o-Vanillin. Dalt. Trans. 2015, 44, 16633-16653.

(10) Gayathri, N.; Raychaudhuri, A. K.; Tiwary, S. K.; Gundakaram, R.; Arulraj, A.; Rao, C. N. R. Electrical Transport, Magnetism, and Magnetoresistance in Ferromagnetic Oxides with Mixed Exchange Interactions: A Study of the $\mathrm{La}_{0.7} \mathrm{Ca}_{0.3} \mathrm{Mn}_{1-\mathrm{x}} \mathrm{Co}_{\mathrm{x}} \mathrm{O}_{3}$ System. Phys. Rev. B: Condens. Matter Mater. Phys. 1997, 56, 1345.

(11) Maeda, H.; Tanaka, Y.; Fukutomi, M.; Asano, T. A New HighTc Oxide Superconductor without a Rare Earth Element. Jpn. J. Appl. Phys. 1988, 27, L209.

(12) Wachs, I. E. Recent Conceptual Advances in the Catalysis Science of Mixed Metal Oxide Catalytic Materials. Catal. Today 2005, 100, 79-94.

(13) Blasse, G. On the $\mathrm{Eu}^{3+}$ Fluorescence of Mixed Metal Oxides. IV. The Photoluminescent Efficiency of $\mathrm{Eu}^{3+}$-activated Oxides. J. Chem. Phys. 1966, 45, 2356-2360.

(14) Veith, M.; Mathur, S.; Lecerf, N.; Huch, V.; Decker, T.; Beck, H. P.; Eiser, W.; Haberkorn, R. Sol-Gel Synthesis of Nano-Scaled $\mathrm{BaTiO}_{3}, \mathrm{BaZrO}_{3}$ and $\mathrm{BaTi}_{0.5} \mathrm{Zr}_{0.5} \mathrm{O}_{3}$ Oxides via Single-Source Alkoxide Precursors and Semi-Alkoxide Routes. J. Sol-Gel Sci. Technol. 2000, 17, 145-158.

(15) Holonyak, N., Jr; Kolbas, R. M.; Dupuis, R. D.; Dapkus, P. D. Room-temperature Continuous Operation of Photopumped MOCVD $\mathrm{Al}_{\mathrm{x}} \mathrm{Ga}_{1-\mathrm{x}} \mathrm{As}-\mathrm{GaAs}-\mathrm{Al}_{\mathrm{x}} \mathrm{Ga}_{1-\mathrm{x}}$ As Quantum-well Lasers. Appl. Phys. Lett. 1978, 33, 73-75.

(16) Hubert-Pfalzgraf, L. G. Metal Alkoxides and $\beta$-diketonates as Precursors for Oxide and Non-oxide Thin Films. Appl. Organomet. Chem. 1992, 6, 627-643.

(17) Marchand, P.; Carmalt, C. J. Molecular Precursor Approach to Metal Oxide and Pnictide Thin Films. Coord. Chem. Rev. 2013, 257, 3202-3221. 
(18) Gschwind, F.; Sereda, O.; Fromm, K. M. Multitopic Ligand Design: A Concept for Single-Source Precursors. Inorg. Chem. 2009, 48, 10535-10547.

(19) Tahir, A. A.; Molloy, K. C.; Mazhar, M.; Kociok-Köhn, G.; Hamid, M.; Dastgir, S. Synthesis and Structural Characterization of a New Heterobimetallic Coordination Complex of Barium and Cobalt for Use as a Precursor for Chemical Vapor Deposition. Inorg. Chem. 2005, 44, 9207-9212.

(20) Ould-Ely, T.; Thurston, J. H.; Whitmire, K. H. Heterobimetallic Bismuth-transition Metal Coordination Complexes as Single-Source Molecular Precursors for the Formation of Advanced Oxide Materials. C. R. Chim. 2005, 8, 1906-1921.

(21) Patil, R.; Kelkar, S.; Naphade, R.; Ogale, S. Low Temperature Grown $\mathrm{CuBi}_{2} \mathrm{O}_{4}$ with Flower Morphology and Its Composite with $\mathrm{CuO}$ Nanosheets for Photoelectrochemical Water Splitting. J. Mater. Chem. A 2014, 2, 3661-3668.

(22) Gkaniatsou, E. I.; Banti, C. N.; Kourkoumelis, N.; Skoulika, S.; Manoli, M.; Tasiopoulos, A. J.; Hadjikakou, S. K. Novel Mixed Metal $\mathrm{Ag}(\mathrm{I})-\mathrm{Sb}(\mathrm{III})-$ Metallotherapeutics of the NSAIDs, Aspirin and Salicylic Acid: Enhancement of Their Solubility and Bioactivity by Using the Surfactant CTAB. J. Inorg. Biochem. 2015, 150, 108-119.

(23) Wright, G. D. Bacterial Resistance to Antibiotics: Enzymatic Degradation and Modification. Adv. Drug Delivery Rev. 2005, 57, $1451-1470$.

(24) Garza-Cervantes, J. A.; Chávez-Reyes, A.; Castillo, E. C.; García-Rivas, G.; Ortega-Rivera, O. A.; Salinas, E.; Ortiz-Martínez, M.; Gómez-Flores, S. L.; Peña-Martínez, J. A.; Pepi-Molina, A.; et al. Synergistic Antimicrobial Effects of Silver/Transition-Metal Combinatorial Treatments. Sci. Rep. 2017, 7, 903.

(25) Varisco, M.; Khanna, N.; Brunetto, P. S.; Fromm, K. M. New Antimicrobial and Biocompatible Implant Coating with Synergic Silver-vancomycin Conjugate Action. ChemMedChem 2014, 9, $1221-1230$.

(26) Zhitnitsky, D.; Rose, J.; Lewinson, O. The Highly Synergistic, Broad Spectrum, Antibacterial Activity of Organic Acids and Transition Metals. Sci. Rep. 2017, 7, 44554.

(27) Cottarel, G.; Wierzbowski, J. Combination Drugs, an Emerging Option for Antibacterial Therapy. Trends Biotechnol. 2007, 25, 547555 .

(28) Gavrilova, A. L.; Bosnich, B. Principles of Mononucleating and Binucleating Ligand Design. Chem. Rev. 2004, 104, 349-384.

(29) Akine, S.; Akimoto, A.; Shiga, T.; Oshio, H.; Nabeshima, T. Synthesis, Stability, and Complexation Behavior of Isolable SalenType $\mathrm{N}_{2} \mathrm{~S}_{2}$ and $\mathrm{N}_{2} \mathrm{SO}$ Ligands Based on Thiol and Oxime Functionalities. Inorg. Chem. 2008, 47, 875-885.

(30) Kleij, A. W. Zinc-Centred Salen Complexes: Versatile and Accessible Supramolecular Building Motifs. Dalt. Trans. 2009, 38, 4635-4639.

(31) Modak, R.; Sikdar, Y.; Cosquer, G.; Chatterjee, S.; Yamashita, M.; Goswami, S. Heterometallic Cu ${ }^{\text {II }}-$ Dy ${ }^{\text {III }}$ Clusters of Different Nuclearities with Slow Magnetic Relaxation. Inorg. Chem. 2016, 55, 691-699.

(32) Lü, X.; Wong, W.; Wong, W. Self-Assembly of Luminescent Platinum-Salen Schiff-Base Complexes. Eur. J. Inorg. Chem. 2008, 2008, 523-528.

(33) Finelli, A.; Hérault, N.; Crochet, A.; Fromm, K. M. Compartmentalization of Alkaline Earth Metals in Salen-type Cuand Ni-Complexes in Solution and in the Solid State. ACS Omega 2019, 4, 10231-10242.

(34) Lyskov, N. V.; Metlin, Y. G.; Belousov, V. V.; Tretyakov, Y. D. Microstructure Evolution and Conductivity of $\mathrm{Bi}_{2} \mathrm{CuO}_{4}-\mathrm{Bi}_{2} \mathrm{O}_{3}$ Composites Nearby the Eutectic Point. Solid State Ionics 2004, 173, 135-139.

(35) Njagi, E. C.; Chen, C.-H.; Genuino, H.; Galindo, H.; Huang, H.; Suib, S. L. Total Oxidation of CO at Ambient Temperature Using Copper Manganese Oxide Catalysts Prepared by a Redox Method. Appl. Catal., B 2010, 99, 103-110.

(36) Correia, I.; Pessoa, J. C.; Duarte, M. T.; da Piedade, M.; Jackush, T.; Kiss, T.; Castro, M.; Geraldes, C. F. G. C.; Avecilla, F.
Vanadium (IV and V) Complexes of Schiff Bases and Reduced Schiff Bases Derived from the Reaction of Aromatic O-Hydroxyaldehydes and Diamines: Synthesis, Characterisation and Solution Studies. Eur. J. Inorg. Chem. 2005, 2005, 732-744.

(37) Majumder, S.; Koner, R.; Lemoine, P.; Nayak, M.; Ghosh, M.; Hazra, S.; Lucas, C. R.; Mohanta, S. Role of Coordinated Water and Hydrogen-Bonding Interactions in Stabilizing MonophenoxidoBridged Triangular $\mathrm{Cu}^{\mathrm{II}} \mathrm{M}^{\mathrm{II}} \mathrm{Cu}^{\mathrm{II}}$ Compounds $(\mathrm{M}=\mathrm{Cu}, \mathrm{Co}, \mathrm{Ni}$, or $\mathrm{Fe}$ ) Derived from $\mathrm{N}, \mathrm{N}^{\prime}$-Ethylenebis (3-methoxysalicylaldimine): Syntheses, Structures, and Magnetic Propert. Eur. J. Inorg. Chem. 2009, 2009, 3447-3457.

(38) Sarkar, S.; Nayak, M.; Fleck, M.; Dutta, S.; Flörke, U.; Koner, R.; Mohanta, S. Syntheses, Crystal Structures and Mass Spectrometry of Mononuclear $\mathrm{Ni}^{\mathrm{II}}$ Inclusion Product and Self-Assembled $[2 \times 1+1$ $\times 2] \mathrm{Ni}_{3}{ }_{3} \mathrm{M}^{\mathrm{II}}(\mathrm{M}=\mathrm{Cu}, \mathrm{Ni}, \mathrm{Co}, \mathrm{Fe}$ or $\mathrm{Mn})$ Cocrystals Derived from N, $\mathrm{N}^{\prime}$-Ethylenebis (3-ethoxysalicylaldimine). Eur. J. Inorg. Chem. 2010, 735-743.

(39) Cosier, J. t; Glazer, A. M. A Nitrogen-Gas-Stream Cryostat for General X-Ray Diffraction Studies. J. Appl. Crystallogr. 1986, 19, 105107.

(40) Blanc, E.; Schwarzenbach, D.; Flack, H. D. The Evaluation of Transmission Factors and Their First Derivatives with Respect to Crystal Shape Parameters. J. Appl. Crystallogr. 1991, 24, 1035-1041.

(41) Sheldrick, G. M. SHELX-97, Program for the Solution and Refinement of Crystal Structures; University of Göttingen, Germany. 1997.

(42) Biswas, A.; Mondal, S.; Mandal, L.; Jana, A.; Chakraborty, P.; Mohanta, S. Exploration of Heterometallic Systems Containing Silver(I) in Acyclic Schiff Base Ligands: Finite and Infinite SelfAssemblies as a Result of Silver(I)-carbon Bond and Silver(I)... Silver(I) Interaction. Inorg. Chim. Acta 2014, 414, 199-209.

(43) Liu, W.; Thorp, H. H. Bond Valence Sum Analysis of MetalLigand Bond Lengths in Metalloenzymes and Model Complexes. 2. Refined Distances and Other Enzymes. Inorg. Chem. 1993, 32, 41024105.

(44) Kriechbaum, M.; Hölbling, J.; Stammler, H.-G.; List, M.; Berger, R. J. F.; Monkowius, U. Unprecedented Large Temperature Dependence of Silver(I)-Silver(I) Distances in Some N-Heterocyclic Carbene Silver(I) Complex Salts. Organometallics 2013, 32, 28762884.

(45) Shannon, R. D. Revised Effective Ionic Radii and Systematic Studies of Interatomic Distances in Halides and Chalcogenides. Acta Crystallogr., Sect. A: Cryst. Phys., Diffr., Theor. Gen. Crystallogr. 1976, 32, $751-767$.

(46) Ma, P.; Geng, Q.; Gao, X.; Yang, S.; Liu, G. Aqueous SolutionChemical Derived Spinel $\mathrm{Cu}_{1.5} \mathrm{Mn}_{1.5} \mathrm{O}_{4}$ Thin Film for Solar Absorber Application. Mater. Lett. 2016, 179, 170-174.

(47) Abdulkarem, A. M.; Li, J.; Aref, A. A.; Ren, L.; Elssfah, E. M.; Wang, H.; Ge, Y.; Yu, Y. $\mathrm{CuBi}_{2} \mathrm{O}_{4}$ Single Crystal Nanorods Prepared by Hydrothermal Method: Growth Mechanism and Optical Properties. Mater. Res. Bull. 2011, 46, 1443-1450.

(48) Janson, O.; Rosner, H. Electronic Structure and Magnetic Properties of $\mathrm{Bi}_{2} \mathrm{CuO}_{4}$. Phys. C 2007, 460, 458-459.

(49) Anandan, S.; Lee, G.-J.; Yang, C.-K.; Ashokkumar, M.; Wu, J. J. Sonochemical Synthesis of $\mathrm{Bi}_{2} \mathrm{CuO}_{4}$ Nanoparticles for Catalytic Degradation of Nonylphenol Ethoxylate. Chem. Eng. J. 2012, 183, 46-52.

(50) Martin, B. E.; Petric, A. Electrical Properties of Coppermanganese Spinel Solutions and Their Cation Valence and Cation Distribution. J. Phys. Chem. Solids 2007, 68, 2262-2270.

(51) Ismail, F. M.; Hamad, F. F.; Faraj, H. S. Electrical Conductivity of Some Copper Manganites. Z. Phys. Chem. 2003, 217, 667-676.

(52) Gupta, M.; Yadav, P.; Khan, W.; Azam, A.; Naqvi, A. H.; Kotnala, R. K. Low Temperature Synthesis and Magneto Resistance

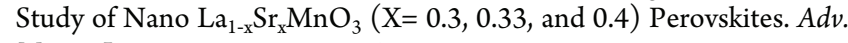
Mater. Lett. 2012, 3, 220-225.

(53) Hallstedt, B.; Risold, D.; Gauckler, L. J. Thermodynamic Evaluation of the Bi-Cu-O System. J. Am. Ceram. Soc. 1996, 79, 353358. 
(54) Arai, T.; Yanagida, M.; Konishi, Y.; Iwasaki, Y.; Sugihara, H.; Sayama, K. Efficient Complete Oxidation of Acetaldehyde into $\mathrm{CO}_{2}$ over $\mathrm{CuBi}_{2} \mathrm{O}_{4} / \mathrm{WO}_{3}$ Composite Photocatalyst under Visible and UV Light Irradiation. J. Phys. Chem. C 2007, 111, 7574-7577.

(55) Turner, R. J. Metal-based antimicrobial strategies. Microb. Biotechnol. 2017, 10, 1062-1065.

(56) Hérault, N.; Wagner, J.; Abram, S.-L.; Widmer, J.; Horvath, L.; Vanhecke, D.; Bourquin, C.; Fromm, K. M. Silver-Containing Titanium Dioxide Nanocapsules for Combating Multidrug-Resistant Bacteria. Int. J. Nanomed. 2020, 15, 1267-1281. 